\title{
ATR kinase inhibitor AZD6738 potentiates CD8+ T cell-dependent antitumor activity following radiation
}

\author{
Frank P. Vendetti, ${ }^{1}$ Pooja Karukonda, ${ }^{1}$ David A. Clump, ${ }^{1}$ Troy Teo, ${ }^{1}$ Ronald Lalonde, ${ }^{1}$ Katriana Nugent, ${ }^{2}$ Matthew Ballew, ${ }^{2}$ \\ Brian F. Kiesel, ${ }^{3}$ Jan H. Beumer, ${ }^{3}$ Saumendra N. Sarkar,, ${ }^{4,5}$ Thomas P. Conrads, ${ }^{6}$ Mark J. O'Connor, ${ }^{7}$ Robert L. Ferris, ${ }^{5,8}$ \\ Phuoc T. Tran, ${ }^{2}$ Greg M. Delgoffe, ${ }^{4}$ and Christopher J. Bakkenist ${ }^{1,9}$

\begin{abstract}
'Department of Radiation Oncology, University of Pittsburgh School of Medicine, Pittsburgh, Pennsylvania, USA. ²Departments of Radiation Oncology and Molecular Radiation Sciences, Medical Oncology and Urology, Program in Cellular and Molecular Medicine, Johns Hopkins University, Baltimore, Maryland, USA. ${ }^{3}$ Department of Pharmaceutical Sciences, University of Pittsburgh School of Pharmacy, Pittsburgh, Pennsylvania, USA. ${ }^{4}$ Department of Microbiology and Molecular Cenetics and ${ }^{5}$ Department of Immunology, University of Pittsburgh School of Medicine, Pittsburgh, Pennsylvania, USA. ${ }^{6}$ nnova Schar Cancer Institute, Inova Center for Personalized Health, Falls Church, Virginia, USA. DNA Damage Response Biology Area, Oncology IMED, AstraZeneca, Cambridge, United Kingdom. ${ }^{8}$ Department of Otolaryngology and ${ }^{9}$ Department of Pharmacology and Chemical Biology, University of Pittsburgh School of Medicine, Pittsburgh, Pennsylvania, USA
\end{abstract}

\begin{abstract}
DNA-damaging chemotherapy and radiation therapy are integrated into the treatment paradigm of the majority of cancer patients. Recently, immunotherapy that targets the immunosuppressive interaction between programmed death 1 (PD-1) and its ligand PD-L1 has been approved for malignancies including non-small cell lung cancer, melanoma, and head and neck squamous cell carcinoma. ATR is a DNA damage-signaling kinase activated at damaged replication forks, and ATR kinase inhibitors potentiate the cytotoxicity of DNA-damaging chemotherapies. We show here that the ATR kinase inhibitor AZD6738 combines with conformal radiation therapy to attenuate radiation-induced $C D 8^{+} T$ cell exhaustion and potentiate CD8+ $T$ cell activity in mouse models of Kras-mutant cancer. Mechanistically, AZD6738 blocks radiation-induced PD-L1 upregulation on tumor cells and dramatically decreases the number of tumor-infiltrating Tregs. Remarkably, AZD6738 combines with conformal radiation therapy to generate immunologic memory in complete responder mice. Our work raises the possibility that a single pharmacologic agent may enhance the cytotoxic effects of radiation while concurrently potentiating radiation-induced antitumor immune responses.
\end{abstract}

\section{Introduction}

The association of programmed death 1 (PD-1) and programmed death ligand 1 (PD-L1) generates an immune checkpoint that is frequently co-opted by tumor cells to evade cytotoxic immune cells $(1,2)$. PD-1 is a cell surface coinhibitory molecule expressed on activated $\mathrm{CD} 4^{+}$and $\mathrm{CD} 8^{+} \mathrm{T}$ cells, B cells, monocytes, natural killer cells, and some dendritic cells (3). Elevated expression of PD-1 is associated with a dysfunctional phenotype known as $\mathrm{T}$ cell exhaustion (4). PD-L1 is a transmembrane protein that is undetectable in most normal tissues, but is induced by inflammatory cytokines, especially type I and type II IFNs (5-8). Accordingly, PD-L1 expression is increased after ionizing radiation (IR), and this may limit antitumor immunity and facilitate relapse (9). PD1/PD-L1 immune checkpoint blockade induces responses in $12 \%-18 \%$ of non-small cell lung cancer and head and neck cancer patients (10-12).

Radiation therapy is integrated into the management of many cancers, and while the effects of radiation within the target volume are well described with DNA damage leading to cell death and senescence (13), the effects of radiation on immune responses are variable in preclinical models, and clinical data are sparse. Radiation can augment $\mathrm{CD}^{+} \mathrm{T}$ cell responses within the tumor

Conflict of interest: MJO is a full-time employee of AstraZeneca. Submitted: July 26, 2017; Accepted: June 26, 2018.

Reference information: / Clin Invest. 2018;128(9):3926-3940.

https://doi.org/10.1172/JCI96519. microenvironment through increased MHC class I and neoantigen expression (14-17). Radiation can also augment immunosuppressive aspects of the tumor microenvironment by recruiting regulatory T cells (Tregs) and inducing PD-L1 expression $(9,18,19)$. Nevertheless, radiation therapy and immunotherapy are considered a promising combination, and anti-PD-L1 antibody increases the efficacy of radiation through a $\mathrm{T}$ cell-dependent mechanism in syngeneic mouse models of breast and colon cancer (9), melanoma (20), and glioblastoma (21), and in genetically engineered mouse models (GEMMs) of Kras-mutant lung cancer (22). Furthermore, acquired resistance to radiation therapy can be reversed by anti-PD-L1 antibody (19).

ATR is an essential DNA damage-signaling kinase activated at damaged replication forks and resected DNA double-strand breaks (23-25). ATR kinase inhibitors sensitize cancer cells to cisplatin and IR in tissue culture (26-30). ATR kinase activity is also increased by hypoxia, and ATR kinase inhibitors sensitize radiation-resistant hypoxic cells to radiation (30-33). Two ATR kinase inhibitors, AZD6738 (34) and M6620 (formerly VX970, VX822) (35), have advanced to the clinic, and patients are currently being enrolled into 10 trials of AZD6738 (e.g., ref. 36). AZD6738 is an ATP-competitive, orally bioavailable pharmaceutical that inhibits ATR kinase activity with an $\mathrm{IC}_{50}$ of 0.001 $\mu \mathrm{M}$ in vitro, while showing no significant inhibition of 442 other kinases at $1 \mu \mathrm{M}(34,37)$. AZD6738 has a significantly higher $\mathrm{IC}_{50}$ against PI3Ks in vitro $\left(\mathrm{IC}_{50} 6.8 \mu \mathrm{M}\right.$ against $\mathrm{PI} 3 \mathrm{~K} \delta$ and $>50 \mu \mathrm{M}$ against $\mathrm{PI} 3 \mathrm{~K} \alpha, \mathrm{PI} 3 \mathrm{~K} \beta$, and $\mathrm{PI} 3 \mathrm{~K} \gamma$; unpublished observations). In 
A

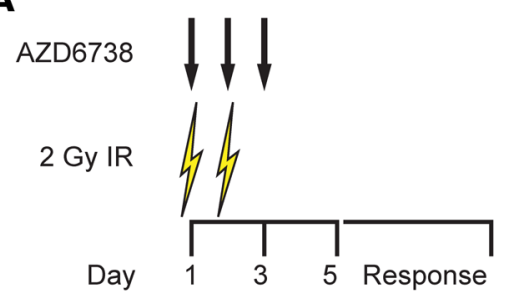

C

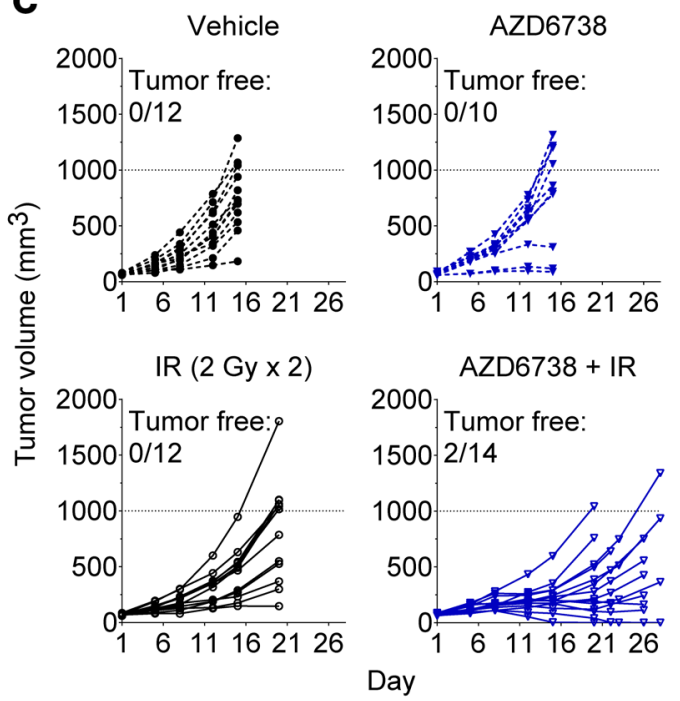

B

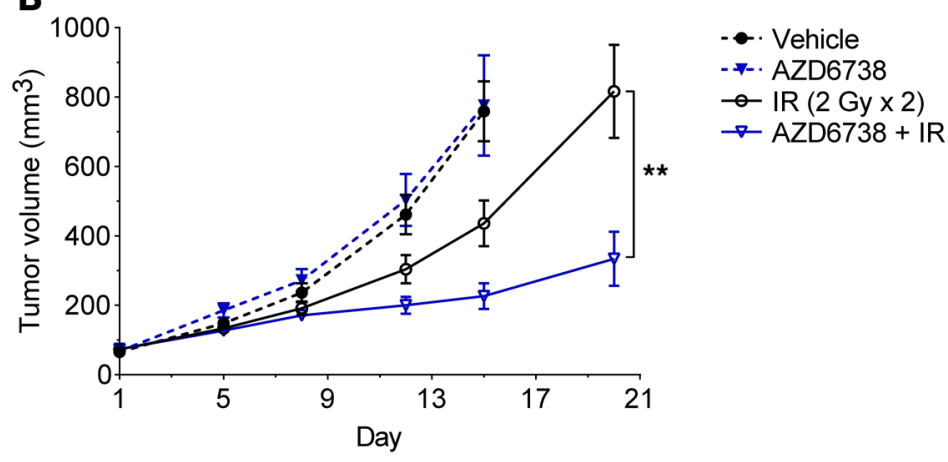

D

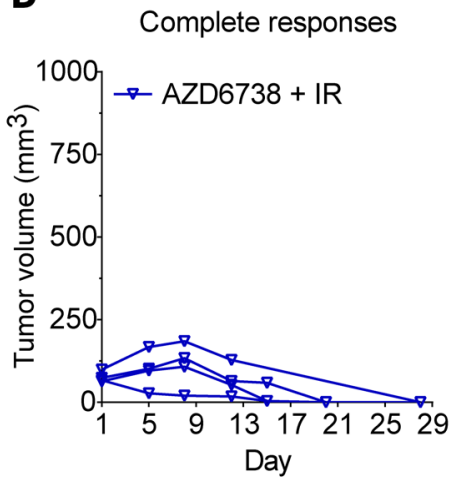

E

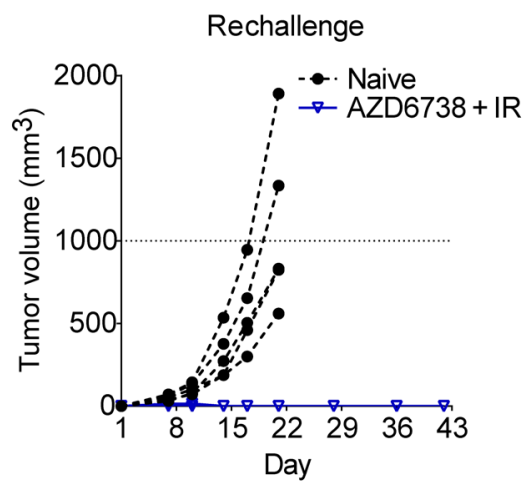

Figure 1. AZD6738 potentiates radiation in syngeneic CT26 tumors and promotes immunologic memory following complete responses. (A) Schematic showing schedules of the ATR kinase inhibitor AZD6738 and targeted radiation (IR). AZD6738 $(75 \mathrm{mg} / \mathrm{kg})$ was administered approximately 40 minutes before IR on days 1-2 and alone on day 3. (B and C) Response of CT26 over time to treatment with AZD6738, IR, or the combination of AZD6738 plus IR. Data represent mean tumor volumes \pm SEM (B) or individual tumor volumes (C) from 2 independent experiments. $n$ per arm (mice) $=12$ vehicle, 10 AZD6738, 12 IR, 14 AZD6738 + IR. ${ }^{* *} P<0.01$, unpaired, 2-tailed $t$ test comparing change in tumor volume from day 1 to day 20 for AZD6738 + IR vs. IR. Statistical significance not shown for other time points. (D) Complete responses of CT26 tumors over time to treatment with AZD6738 plus IR. (E) Tumor growth following rechallenge of complete responder mice with CT26 cells in the contralateral flank compared with tumor growth in CT26-naive control mice. ( $\mathbf{D}$ and $\mathbf{E}$ ) Data represent individual tumor volumes. $n$ per arm (mice) $=4$ AZD6738 + IR complete responders, 5 naive controls.

cells, AZD6738 inhibits ATR kinase-dependent phosphorylation of CHK1 Ser345 with an $\mathrm{IC}_{50}$ of $0.074 \mu \mathrm{M}$, but does not significantly inhibit the related PI3K-related kinases ATM, DNA$\mathrm{PK}$, and mTOR $\left(\mathrm{IC}_{50}>5 \mu \mathrm{M}\right)$ (37). We have previously shown that AZD6738 does not sensitize mice to total-body irradiation (38). Here we show that, quite unexpectedly, AZD6738 combines with conformal radiation to potentiate $\mathrm{CD} 8^{+} \mathrm{T}$ cell activity in the tumor microenvironment in a syngeneic and a genetically engineered mouse model of cancer.

\section{Results}

AZD6738 plus radiation generates a $C D 8^{+} T$ cell-dependent response in a syngeneic model of colorectal carcinoma. Kras ${ }^{G 12 D}$ CT26 mouse colorectal tumors grown on the flanks of BALB/c mice were treated with the ATR kinase inhibitor AZD6738 $(75 \mathrm{mg} / \mathrm{kg})$ on days 1-3 and 2 Gy conformal radiation on days 1-2 (Figure 1A) (39). AZD6738 was administered approximately 40 minutes before radiation on days 1-2, and pharmacokinetic analysis confirmed distribution of AZD6738 in the plasma, lungs, and tumors of CT26 tumor-bearing mice (Supplemental Figure 1, A and B; supplemental material available online with this article; https:// doi.org/10.1172/JCI96519DS1).
Following treatment with vehicle or AZD6738, the designated tumor volume endpoint was reached by day 15, and AZD 6738 alone had no impact on tumor growth (Figure 1, B and C). At day 15, radiation alone resulted in $47.6 \%$ mean tumor growth inhibition (TGI) relative to vehicle control (mean change in tumor volume from day $1 \pm$ SEM: $362.9 \pm 64.7 \mathrm{~mm}^{3}$ radiation vs. $693.1 \pm 85.4 \mathrm{~mm}^{3}$ vehicle, $P=0.029$ ), while AZD6738 plus radiation resulted in $78.0 \%$ TGI relative to vehicle control $\left(152.4 \pm 36.1 \mathrm{~mm}^{3}\right.$ AZD 6738 plus radiation vs. vehicle, $P=0.0001)$. AZD6738 plus radiation resulted in $58.0 \%$ TGI relative to radiation alone at day 15 , but this difference did not reach statistical significance $(P=0.13)$. By day 20, when the radiation-alone arm reached the experimental endpoint, AZD6738 plus radiation significantly inhibited tumor growth relative to radiation alone $\left(65.0 \%\right.$ TGI, $260.0 \pm 77.3 \mathrm{~mm}^{3}$ AZD 6738 plus radiation vs. $743.4 \pm 132.5 \mathrm{~mm}^{3}$ radiation, $P=0.0036$ ) (Figure $1 \mathrm{~B}$ ). Since the AZD6738 plus radiation arm had not reached the endpoint at day 20 , and we noted regression of several tumors at this time point, we monitored tumor growth for an additional 6 or 8 days. Two of fourteen mice exhibited complete responses to AZD6738 plus radiation in this time frame (Figure 1C).

Given that the delayed impact of AZD6738 on radiation is similar to the delayed impact of anti-PD-L1 antibody on radiation $(9$, 
A

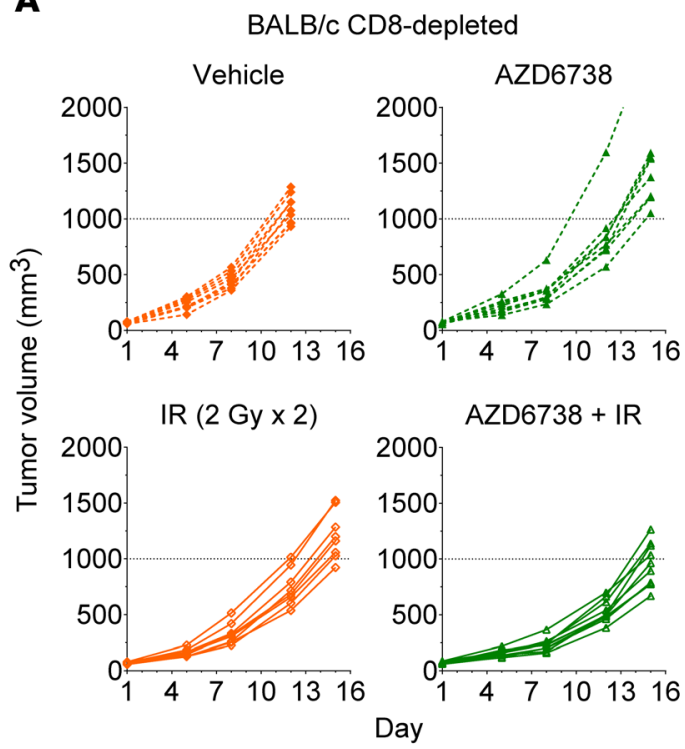

C

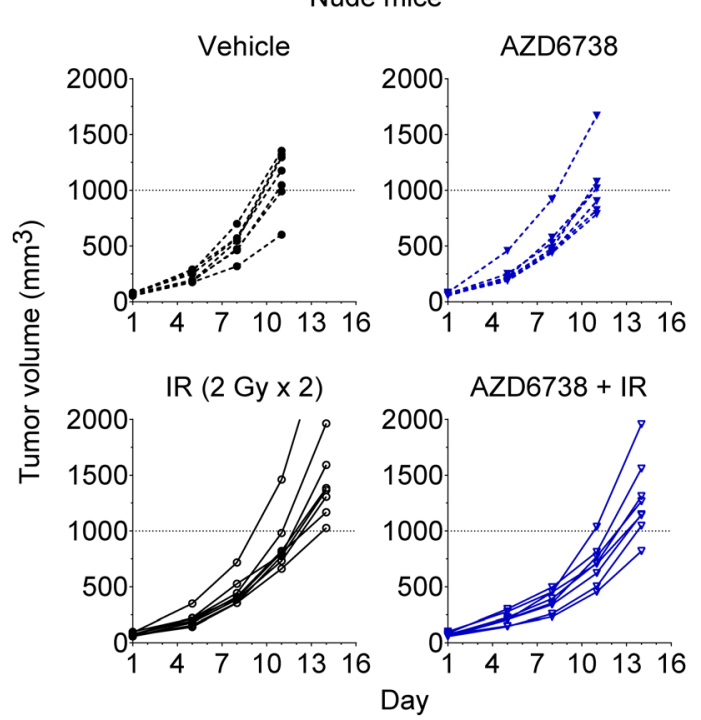

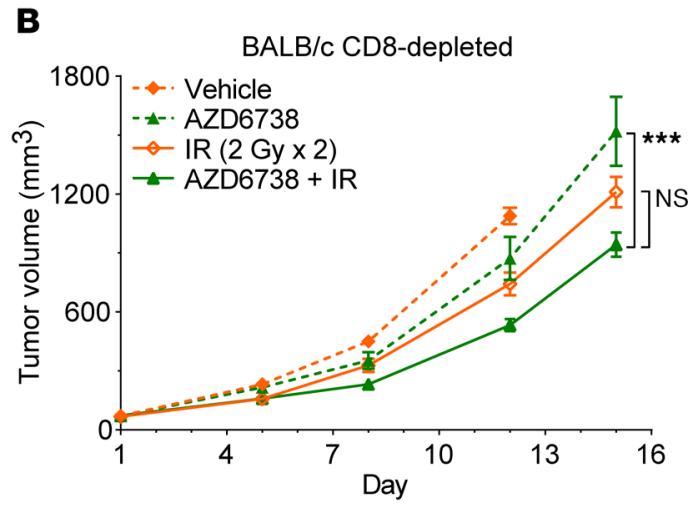

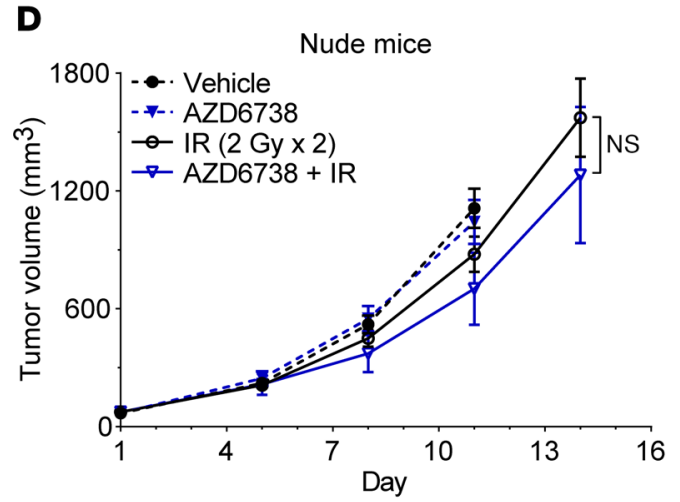

Figure 2. CD8 ${ }^{+}$T cells are required for maximal efficacy of AZD6738 plus radiation in CT26 tumors. (A-D) Response of CT26 over time to treatment with AZD6738, IR, or the combination of AZD6738 plus IR in CD8-depleted BALB/C (A and B) and athymic nude (C and D) mice. Dose and time of administration of AZD6738 were the same as in Figure 1. (A and B) Response in CD-depleted BALB/c mice, with $250 \mu$ anti-CD8 antibody ( $\alpha$ CD8) administered on days 1-2. Data represent individual tumor volumes (A) or mean tumor volumes \pm SEM (B) from 2 independent experiments. $n$ per arm (mice) $=9$ vehicle, 8 AZD6738, 8 IR, 10 AZD6738 + IR. ***P<0.001, ANOVA with Holm-Šidák multiple-comparisons test comparing change in tumor volume from day 1 to day 15 for AZD6738 + IR vs. AZD6738 and AZD6738 + IR vs. IR. Statistical significance not shown for other comparisons/time points. (C and D) Response in athymic nude mice. Data represent individual tumor volumes (C) or mean tumor volumes \pm SEM (D) from 1 experiment. $n$ per arm (mice) $=7$ vehicle, 7 AZD6738, 8 IR, 8 AZD6738 + IR. Unpaired, 2-tailed $t$ test comparing change in tumor volume from day 1 to day 14 for AZD6738 + IR vs. IR. Statistical significance not shown for other time points.

19, 22), and that AZD6738 does not radiosensitize CT26 cells in vitro (Supplemental Figure 2), we hypothesized that the improved efficacy of AZD6738 plus radiation is mediated by the immune system. To test this, we first assessed whether AZD6738 plus radiation treatment resulted in protection of complete responder mice against CT26 tumor rechallenge. We collected complete responder mice over the course of several independent treatments with AZD6738 plus radiation (initial treatment responses shown in Figure 1D). We rechallenged these mice with CT26 cells in the contralateral flank following a tumor-free period of 37-92 days. All complete responder mice rejected CT26 tumors upon rechallenge, while previously tumor-naive BALB/c mice exhibited normal tumor growth (Figure 1E). Therefore, AZD6738 plus radiation promotes immunologic memory in complete responder mice.

PD-1/PD-L1 blockade potentiates radiation in a $\mathrm{CD}^{+} \mathrm{T}$ celldependent manner in the CT26 model (19). To determine whether improved antitumor responses and immunologic memory following treatment with AZD 6738 plus radiation are mediated by $\mathrm{CD} 8^{+}$ $\mathrm{T}$ cells, we depleted cytotoxic $\mathrm{T}$ cells using anti-CD8 antibody. Pilot studies with 2 different dosing schedules of anti-CD8 antibody revealed that depletion of $\mathrm{CD}^{+} \mathrm{T}$ cells significantly accelerates growth of CT26 tumors (Supplemental Figure 3, A-D). As this confounds comparisons of treatments in nondepleted versus CD8-depleted mice, we evaluated responses across treatments in CD8-depleted mice. Tumors in vehicle control mice reached the experimental endpoint by day 12 , at which time radiation alone resulted in $33.7 \%$ TGI relative to vehicle $\left(675.0 \pm 56.6 \mathrm{~mm}^{3}\right.$ radiation vs. 1,018.0 $\pm 41.7 \mathrm{~mm}^{3}$ vehicle, $P=0.0024$ ) (Figure 2, A and B). AZD6738 plus radiation resulted in $54.8 \%$ TGI relative to vehicle $\left(460.4 \pm 28.7 \mathrm{~mm}^{3}\right.$ AZD 6738 plus radiation vs. vehicle, $P<$ 0.0001 ) and $42.5 \%$ TGI relative to AZD6738 alone (42.5\% TGI, vs. $801.1 \pm 109.5 \mathrm{~mm}^{3}$ AZD6738, $\left.P=0.0024\right)$. AZD6738 plus radia- 
A

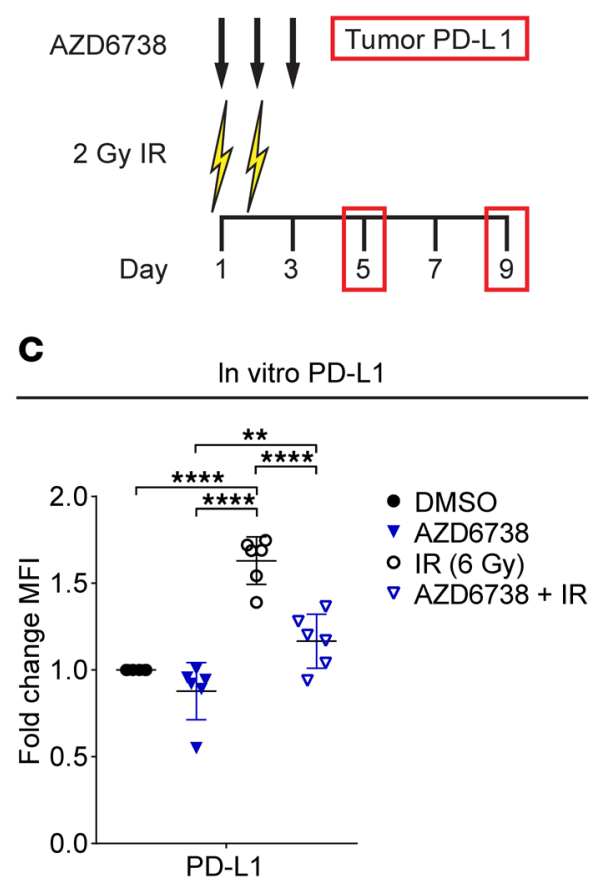

B In vivo PD-L1 day 5

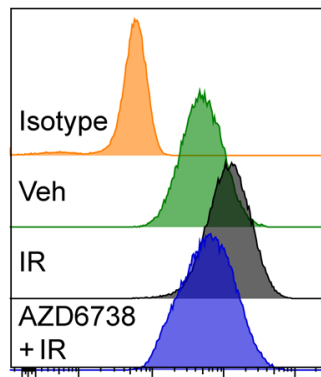

PD-L1

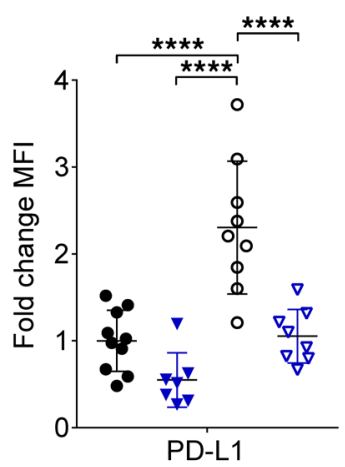

TIL day 5
D

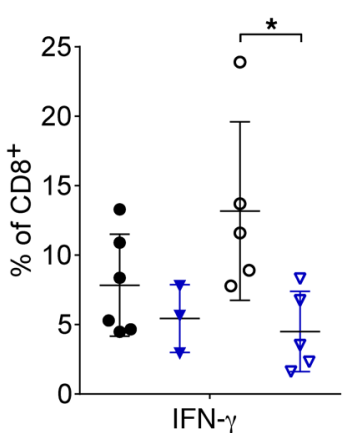

- Vehicle

- AZD6738

- IR (2 Gy x 2)

$\nabla$ AZD6738 + IR

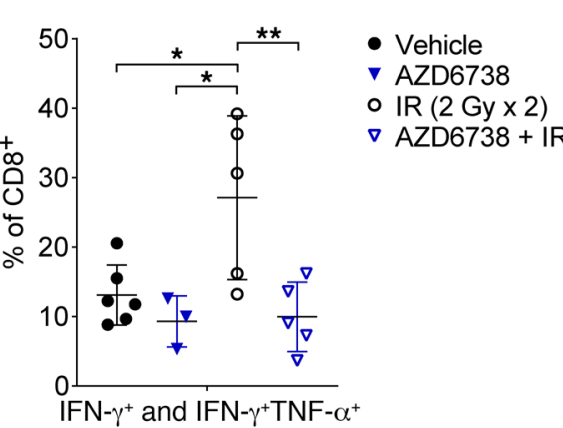

Figure 3. AZD6738 attenuates radiation-induced PD-L1 expression in CT26 tumors. (A) Schematic showing schedules of IR, AZD6738, and time points for tumor PD-L1 expression analyses. Dose and time of administration of AZD6738 were the same as in Figure 1. (B) Representative histograms of PD-L1 expression on CT26 tumor cells at day 5 for the designated treatments and isotype control, and corresponding quantitation of the fold change in PD-L1 median fluorescence intensity (MFI) relative to the average MFI of vehicle controls (within a given experiment). Data from 4 independent experiments (3 for AZD6738), each with 1-4 mice per arm. $n=10$ vehicle, 7 AZD6738, 9 IR, 8 AZD6738 + IR. (C) Quantitation of fold change in PD-L1 MFI following treatment in vitro with AZD6738 (300 nM), 6 Gy IR, AZD6738 plus IR, or DMSO control. Data represent 6 independent biological replicates. (D) Quantitation of the percentage of tumor-infiltrating $\mathrm{CD}^{+}$T cells expressing IFN- $\gamma$ or IFN- $\gamma$ and TNF- $\alpha$ following stimulation with PMA/ionomycin at day 5 . Data from 3 independent experiments (1 for AZD6738), each with 1-3 mice per arm. $n=6$ vehicle, 3 AZD6738, 5 IR, 5 AZD6738 + IR. (B-D) Mean and SD bars shown. ${ }^{*} P<0.05,{ }^{*} P<0.01$, ${ }^{* * *} P<0.0001$, ANOVA with Tukey's multiple-comparisons test. Brackets not shown for comparisons that were not statistically significant.

tion resulted in $31.8 \%$ TGI relative to radiation alone at day 12 , but this difference did not reach statistical significance $(P=0.058)$. By day 15 , at which time all remaining treatment arms reached the experimental endpoint, AZD6738 plus radiation significantly inhibited tumor growth relative to AZD6738 alone (39.9\% TGI, $869.7 \pm 59.6 \mathrm{~mm}^{3}$ AZD6738 plus radiation vs. $1,519.0 \pm 175.6 \mathrm{~mm}^{3}$ AZD6738, $P=0.0009$ ). While AZD6738 plus radiation resulted in $23.9 \%$ TGI relative to radiation alone at day 15 , this difference only trended toward, but did not reach, statistical significance $(P=0.054)$ (Figure 2B).

We also evaluated treatment responses in CT26 tumorbearing athymic nude mice, which are deficient in all mature $\mathrm{T}$ lymphocytes. We observed even greater accelerated CT26 tumor growth in nude mice, as vehicle- and AZD6738-treated tumors reached the experimental endpoint by day 11 (Figure 2, C and D). At this time, only AZD6738 plus radiation resulted in statistically significant TGI relative to vehicle control (39.8\% TGI, $627.7 \pm 65.1$ $\mathrm{mm}^{3}$ AZD6738 plus radiation vs. 1,043.0 $\pm 97.0 \mathrm{~mm}^{3}$ vehicle, $P=$ 0.017). AZD6738 plus radiation resulted in $21.9 \%$ TGI relative to radiation alone, but this difference did not reach statistical significance $(P=0.49)$. By day 14 , AZD6738 plus radiation resulted in
19.5\% TGI relative to radiation alone, but again, the difference did not reach statistical significance (0.23) (Figure 2D).

AZD6738 attenuates radiation-induced $P D-L 1$ expression in CT26 tumors. Radiation induces PD-L1 expression on tumor cells in vivo, and PD-1/PD-L1 blockade synergizes with radiation in some syngeneic models and GEMMs of cancer (9, 19, 22). We examined tumor PD-L1 expression by flow cytometry at days 5 and 9 following treatment with AZD6738 on days 1-3 and 2 Gy radiation on days 1-2 (Figure 3A and Supplemental Figure 4, A and B). At day 5, radiation increased PD-L1 on CD45- cells in vivo 2.30-fold \pm 0.76 -fold (mean fold change in PD-L1 median fluorescence intensity [MFI] \pm SD) compared with vehicle controls $(P<0.0001)$. AZD6738 attenuated radiation-induced PD-L1 (1.05-fold \pm 0.31-fold increase AZD6738 plus radiation vs. 2.30 -fold \pm 0.76 -fold radiation, $P<0.0001$ ) (Figure $3 \mathrm{~B}$ ). By day 9 , radiation-induced tumor $\mathrm{PD}-\mathrm{L} 1$ returned to near vehicle control levels (1.36-fold \pm 0.21 -fold change radiation vs.1.0-fold \pm 0.19 -fold vehicle), while tumor PD-L1 in AZD6738 plus radiation mice was elevated (1.81-fold \pm 0.30-fold increase AZD6738 plus radiation vs. vehicle, $P=0.0002$, or AZD6738 plus radiation vs. radiation, $P=0.027$ ) (Supplemental Figure 4C). 
A
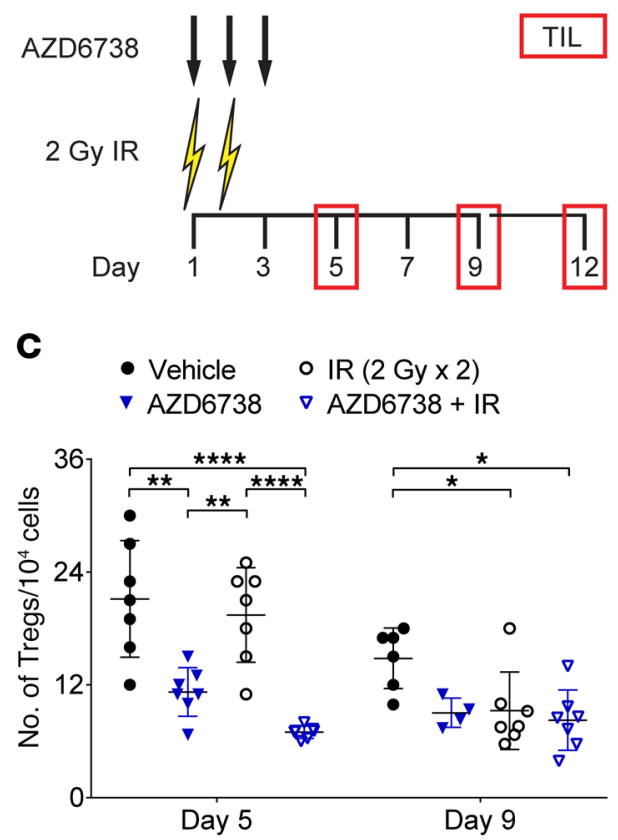

B - Vehicle VAZD6738 ○ IR (2 Gy x 2) $\nabla$ AZD6738 + IR
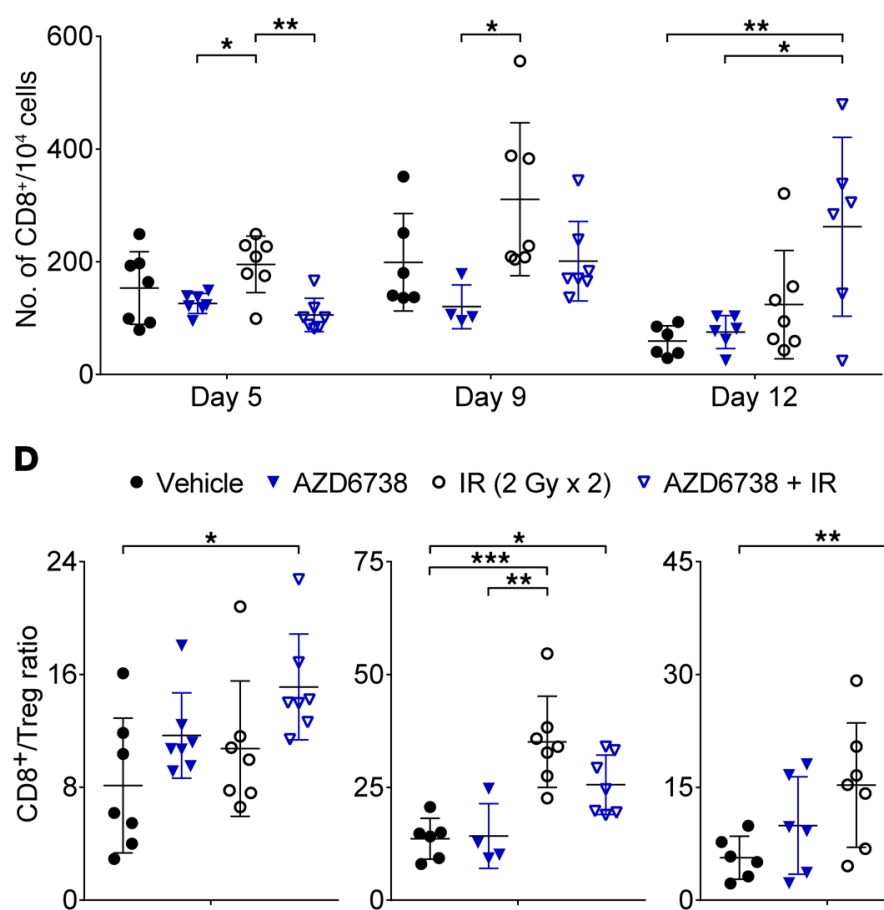

Day 5

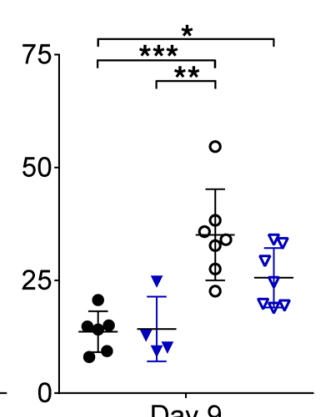

Day 9

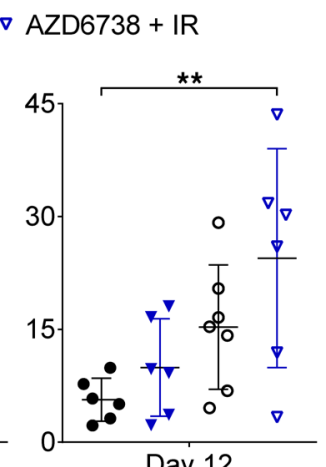

Day 12

Figure 4. AZD6738 impacts T cell infiltration in CT26 tumors following radiation. (A) Schematic showing schedules of IR and AZD6738 treatments and time points for tumor-infiltrating lymphocyte (TIL) analyses. Dose and time of administration of AZD6738 were the same as in Figure 1. (B) Quantitation of the number of TIL CD8 ${ }^{+}$cells per $10^{4}$ cells stained at days 5, 9, and 12. (C) Quantitation of the number of TIL Tregs per $10^{4}$ cells stained at days 5 and 9. (D) $\mathrm{CD}^{+} /$Treg ratios at days 5, 9, and 12. (B-D) Data from 3 independent experiments per time point, each with 1-3 mice per arm. $n$ at day $5=7$ per arm; $n$ at day $9=6$ vehicle, 4 AZD6738, 7 IR, 7 AZD6738 + IR; $n$ at day $12=6$ per arm (7IR). Mean and SD bars shown. ${ }^{*} P<0.05,{ }^{* *} P<0.01,{ }^{* * *} P<0.001$, ${ }^{* * *} P<0.0001$, ANOVA with Tukey's multiple-comparisons test. Brackets not shown for comparisons that were not statistically significant.

DNA double-strand breaks induce PD-L1 expression in human cancer cells in vitro (40). Consistent with this report, radiation increased cell surface expression of PD-L1 on murine CT26 cells in vitro (1.63-fold \pm 0.14 -fold increase radiation vs. DMSO control, $P<0.0001$ ), and this increase was attenuated by $300 \mathrm{nM}$ AZD6738 (1.17-fold \pm 0.16 -fold increase AZD6738 plus radiation vs. radiation, $P<0.0001)$, indicating that the impact of AZD6738 on radiation-induced $\mathrm{PD}-\mathrm{L} 1$ expression is, at least in part, cell intrinsic (Figure 3C).

Radiation-induced PD-L1 expression in CT26 cells in vivo has been attributed to $\mathrm{CD}^{+} \mathrm{T}$ cell-secreted IFN- $\gamma(19)$. We examined the competency of tumor-infiltrating T cells to elicit IFN- $\gamma$, TNF- $\alpha$, and IL-2 following stimulation with phorbol 12-myristate 13-acetate (PMA) and ionomycin at day 5. Compared with radiation alone, AZD6738 plus radiation reduced the percentage of $\mathrm{CD}^{+} \mathrm{T}$ cells that produced only IFN- $\gamma$ following stimulation $(4.5 \% \pm 2.9 \%$ AZD 6738 plus radiation vs. $13.2 \% \pm 6.4 \%$ radiation, $P=0.028$ ) (Figure 3D). In addition, radiation alone increased the percentage of all IFN- $\gamma-$ competent (IFN- $\gamma^{+}$and IFN- $\gamma^{+}$TNF- $\alpha^{+}$) $\mathrm{CD}^{+} \mathrm{T}$ cells at day 5 relative to all other treatment arms $(27.1 \% \pm$ $11.8 \%$ radiation vs. $13.1 \% \pm 4.3 \%$ vehicle, $P=0.026$; vs. $9.3 \% \pm 3.7 \%$ AZD6738, $P=0.019$; vs. $10.0 \% \pm 5.0 \%$ AZD6738 plus radiation, $P=0.009$ ) (Figure 3D). In contrast, we observed no significant differences among treatment groups in the IFN- $\gamma$ competency of $\mathrm{CD}^{+}$effector $\left(\mathrm{CD}^{+}\right.$Eff) $\mathrm{T}$ cells (Supplemental Figure $5 \mathrm{~A}$ ).
Radiation also increased IL-2 production by infiltrating $\mathrm{CD} 8^{+} \mathrm{T}$ cells in comparison with unirradiated controls (1.84-fold \pm 0.34 fold increase radiation vs. 1.26 -fold \pm 0.33 -fold vehicle, $P=0.039$; vs. 0.99-fold \pm 0.14 -fold AZD6738, $P=0.01$ ), but the difference between radiation and AZD6738 plus radiation did not reach statistical significance (Supplemental Figure 5B). No significant differences in IL-2 production by $\mathrm{CD} 4^{+}$Eff $\mathrm{T}$ cells were observed.

Collectively, our data suggest that AZD6738 attenuates both cell-intrinsic PD-L1 upregulation and IFN- $\gamma$-driven upregulation of PD-L1 following radiation. To test whether attenuation of radiation-induced PD-L1 expression by AZD6738 directly contributes to the response of CT26 tumors to AZD6738 plus radiation, we generated PD-L1-knockout CT26 cells using CRISPR (Supplemental Figure 6A). In line with published literature (41), these cells were poorly tumorigenic in vivo, negating the possibility of experimentation, but reaffirming the importance of PD-L1/ $\mathrm{PD}-1$-mediated $\mathrm{T}$ cell suppression for the growth of syngeneic tumors (Supplemental Figure 6B).

AZD6738 impacts $T$ cell infiltration in CT26 tumors following radiation. We enumerated $\mathrm{CT} 26$ tumor-infiltrating $\mathrm{T}$ cells at days 5, 9, and 12 following treatment with AZD6738 on days 1-3 and 2 Gy radiation on days 1-2 (Figure $4 \mathrm{~A}$ ). Radiation alone did not impact the numbers of infiltrating $\mathrm{CD} 8^{+}$or $\mathrm{CD} 4^{+}$Eff $\mathrm{T}$ cells compared with vehicle control (Figure 4B and Supplemental Figure 7A). AZD6738 alone and AZD6738 plus radiation reduced 
A

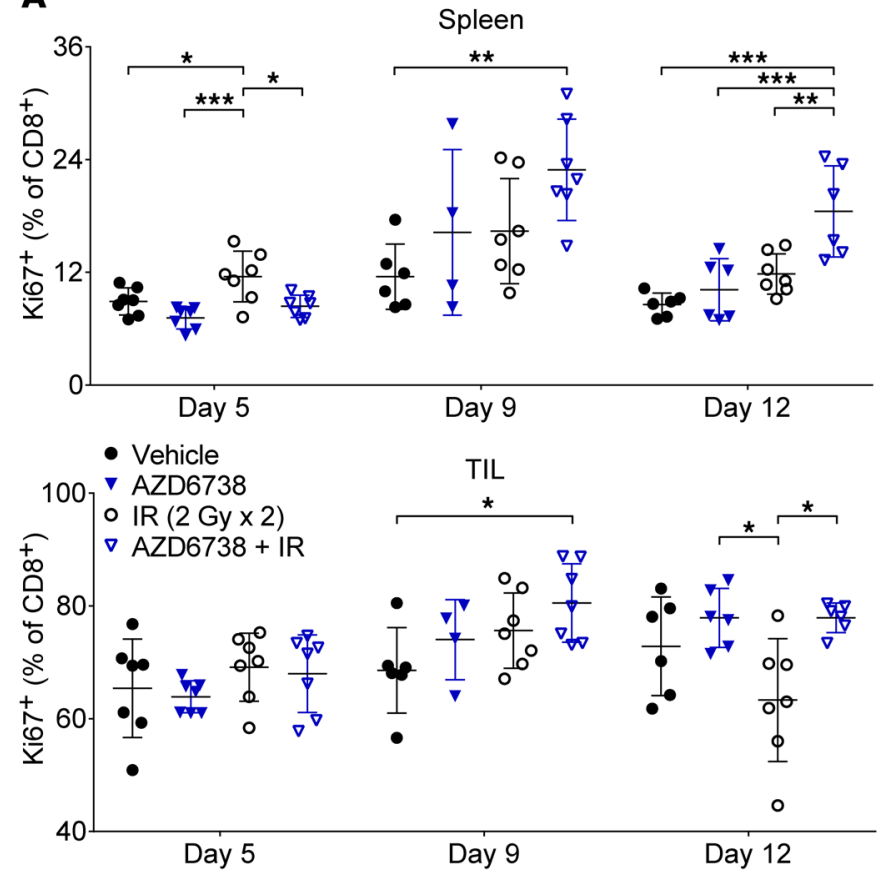

B

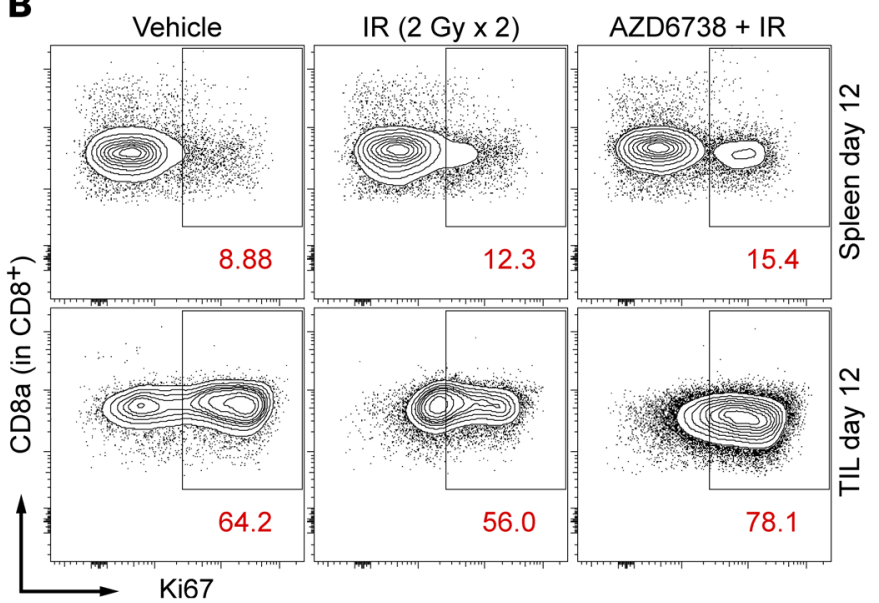

C
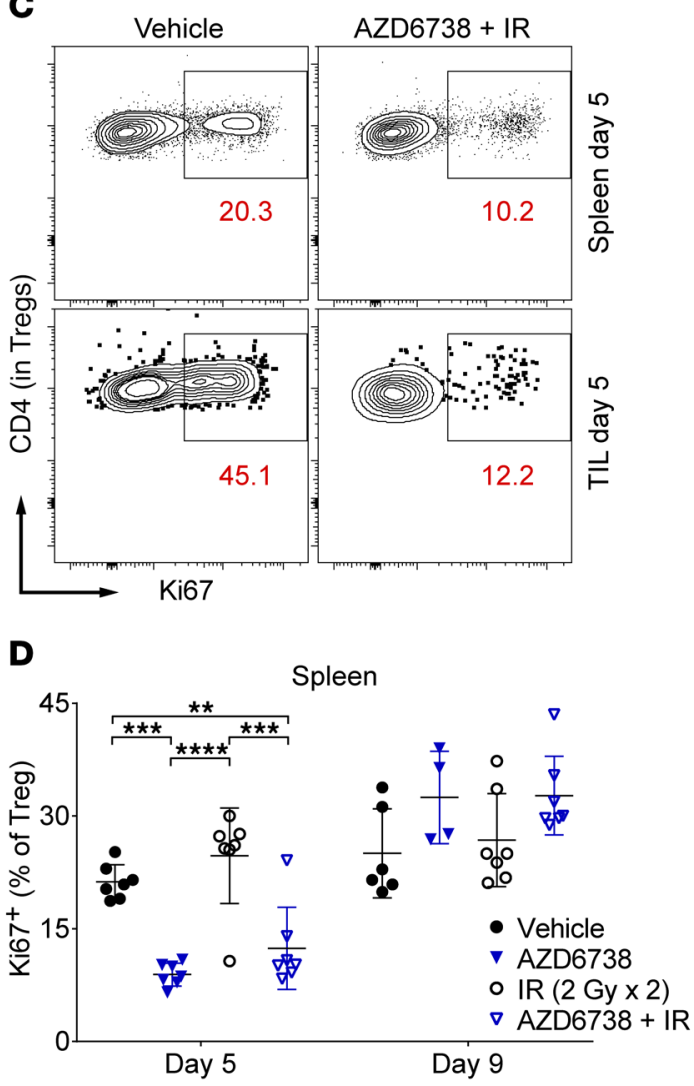

TIL

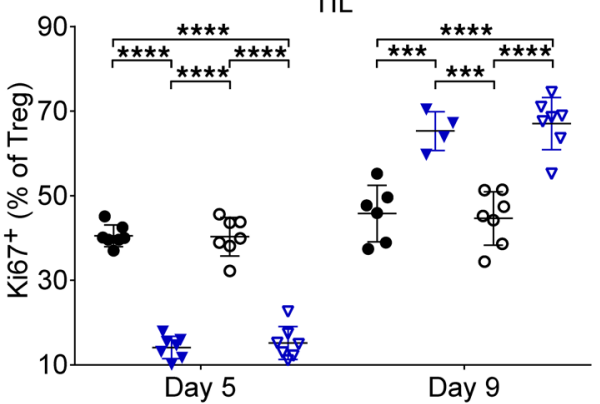

Figure 5. AZD6738 impacts proliferating splenic and tumor-infiltrating T cells in CT26 tumor-bearing mice. (A) Quantitation of the percentages of proliferating $\left(\mathrm{Ki}^{+} 7^{+}\right)$splenic and tumor-infiltrating (TIL) CD8 ${ }^{+}$T cells at days 5, 9, and 12. (B) Representative contour plots depicting Ki67 ${ }^{+}$expression on splenic and TIL CD8 ${ }^{+}$T cells for the designated treatment groups at day 12. (C) Representative contour plots depicting Ki67 ${ }^{+}$expression on splenic and TIL Tregs for the designated treatment groups at day 5. (D) Quantitation of the percentages of proliferating (Ki67+) splenic and TIL Tregs at days 5 and 9 . (B and $\mathbf{D})$ Data from 3 independent experiments per time point, each with 1-3 mice per arm. $n$ at day $5=7$ per arm; $n$ at day $9=6$ vehicle, 4 AZD6738, 7 IR, 7 AZD6738 + IR; $n$ at day $12=6$ per arm (7 IR). Mean and SD bars shown. ${ }^{*} P<0.05,{ }^{* *} P<0.01,{ }^{* *} P<0.001,{ }^{* * *} P<0.0001$, ANOVA with Tukey's multiple-comparisons test. Brackets not shown for comparisons that were not statistically significant.

infiltrating CD8 ${ }^{+} \mathrm{T}$ cells at day 5 compared with radiation alone $(126.0 \pm 17.7$ cells AZD6738 vs. $195.3 \pm 50.3$ cells radiation, $P=$ $0.035 ; 105.6 \pm 29.5$ cells AZD 6738 plus radiation vs. radiation, $P=$ $0.0047)$. At day $9, \mathrm{CD} 8^{+} \mathrm{T}$ cell infiltration was reduced in tumors treated with AZD6738 compared with radiation alone $(120.3 \pm$ 38.8 cells AZD 6738 vs. $310.9 \pm 135.7$ cells radiation, $P=0.022$ ), while infiltration in tumors treated with AZD6738 plus radiation was not different from that in radiation- or vehicle-treated tumors. At day 12, AZD6738 plus radiation increased $\mathrm{CD} 8^{+} \mathrm{T}$ cell infiltration compared with vehicle and AZD 6738 alone $(262.2 \pm 158.7$ cells AZD 6738 plus radiation vs. $59.3 \pm 27.1$ cells vehicle, $P=0.0067$; vs .
$75.2 \pm 29.2$ cells AZD6738, $P=0.013$ ) (Figure 4B). AZD6738 plus radiation led to reduced $\mathrm{CD} 4^{+}$Eff infiltration at days 5 and 9 , but no differences were observed at day 12 (Supplemental Figure 7A).

Striking reductions in infiltrating Tregs were observed at day 5 in tumors treated with AZD6738 or AZD6738 plus radiation (11.2 \pm 2.6 cells AZD 6738 vs. $21.1 \pm 6.2$ cells vehicle, $P=0.001$; and vs. $19.4 \pm 5.0$ cells radiation, $P=0.0067 ; 7.0 \pm 0.7$ cells AZD6738 plus radiation vs. vehicle, $P<0.0001$, and vs. radiation, $P<0.0001$ ). At day 9, both radiation-treated tumors and tumors treated with AZD6738 plus radiation exhibited reduced Treg infiltration compared with vehicle-treated tumors $(9.2 \pm 4.1$ cells radiation vs. 14.8 
A

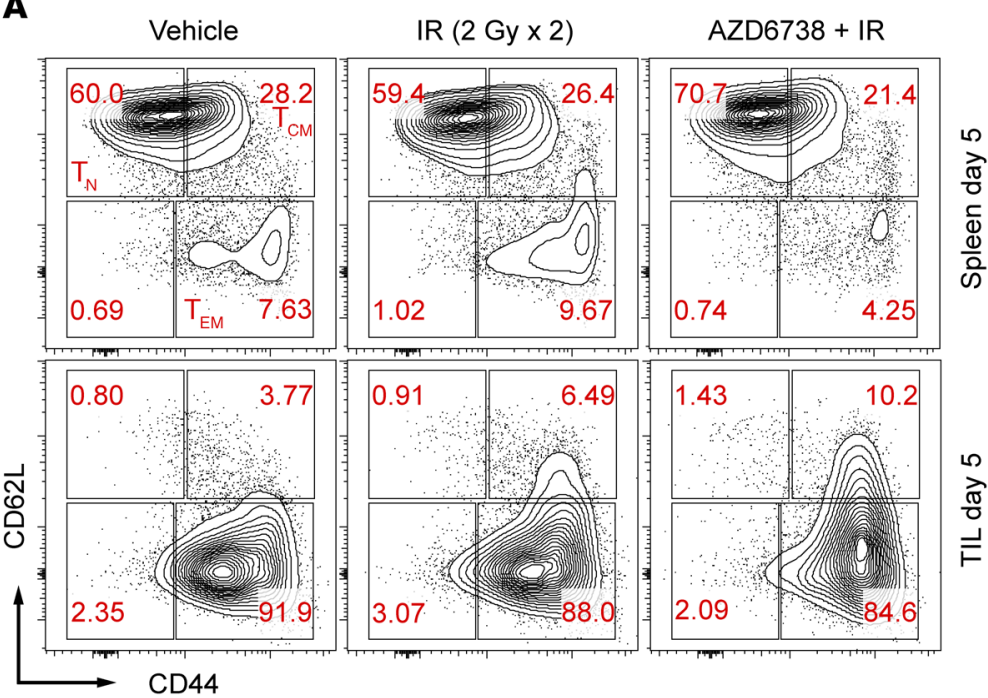

B

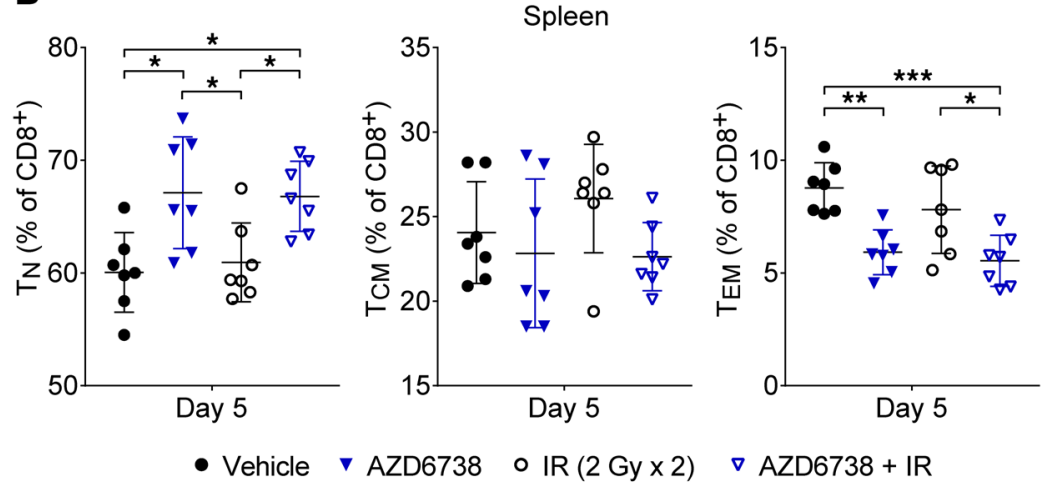

C
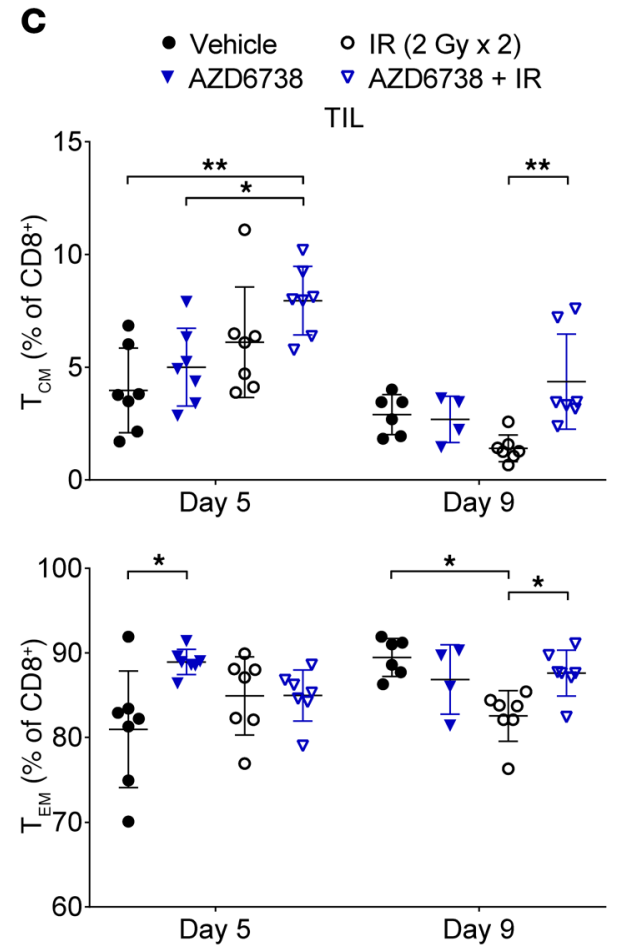

D

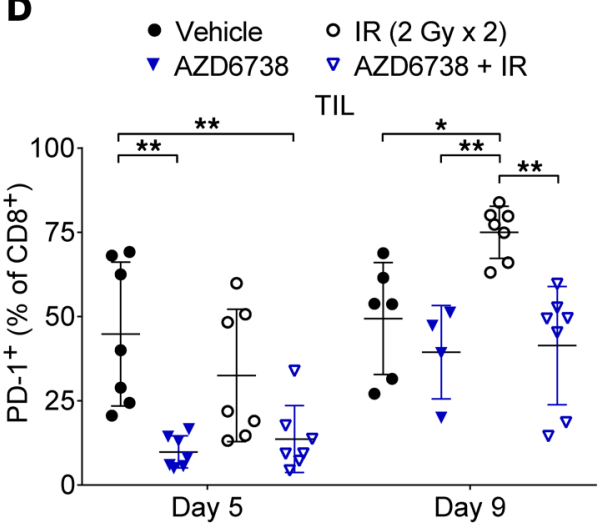

Figure 6. AZD6738 impacts CD8+ T cell activation in CT26 tumor-bearing mice. (A) Representative contour plots depicting CD62L and CD44 expression on spleen and tumor-infiltrating (TIL) CD8 ${ }^{+} T$ cells for the designated treatment groups at day 5. (B) Quantitation of the percentage of splenic CD8 ${ }^{+} T$ cells with naive $\left(T_{N}, C D 62 L^{\text {hi }} C D 44^{10}\right)$, central memory $\left(T_{C M}, C D 62 L^{\text {hi }} C D 44^{\text {hi }}\right)$, or effector memory $\left(T_{E M}, C D 62 L^{\text {lo }} C D 44^{\text {hi }}\right)$ phenotypes at day 5 . (C) Quantitation of the percentage of TIL CD8 ${ }^{+} T$ cells with $T_{C M}$ or $T_{E M}$ phenotypes at days 5 and 9. (D) Quantitation of the percentage of tumor-infiltrating (TIL) CD8 ${ }^{+} T$ cells that express PD-1 at days 5 and 9. (B-D) Data from 3 independent experiments per time point, each with 1-3 mice per arm. $n$ at day $5=7$ per arm; $n$ at day $9=6$ vehicle, 4 AZD6738, 7 IR, 7 AZD6738 + IR. Mean and SD bars shown. ${ }^{*} P<0.05,{ }^{* *} P<0.01,{ }^{* * *} P<0.001$, ANOVA with Tukey's multiple-comparisons test. Brackets not shown for comparisons that were not statistically significant.

\pm 3.2 cells vehicle, $P=0.033 ; 8.2 \pm 3.2$ cells AZD6738 plus radiation vs. vehicle, $P=0.01$ ) (Figure $4 \mathrm{C}$ ). No differences in Treg infiltration were observed at day 12 (Supplemental Figure 7B).

Despite the decrease in infiltrating CD8 ${ }^{+} \mathrm{T}$ cells, AZD6738 plus radiation led to an elevated $\mathrm{CD}^{+} /$Treg ratio at day 5 (15.1 \pm 3.8 AZD6738 plus radiation vs. $8.1 \pm 4.8$ vehicle, $P=0.021$ ) (Figure 4D). At day 9, both radiation alone and AZD6738 plus radiation resulted in elevated $\mathrm{CD}^{+} /$Treg ratios $(35.1 \pm 10.1$ radiation vs. $13.7 \pm 4.5$ vehicle, $P=0.0003 ; 25.6 \pm 6.6$ AZD 6738 plus radiation vs. vehicle, $P=0.045$ ) (Figure 4D). At day 12 , only AZD 6738 plus radiation resulted in an elevated $\mathrm{CD}^{+} /$Treg ratio compared with vehicle control $(24.5 \pm 14.5$ AZD6738 plus radi- ation vs. $5.7 \pm 2.9$ vehicle, $P=0.0084$ ) (Figure $4 \mathrm{D}$ ). The CD $4^{+}$ Eff/Treg ratio was also elevated at day 5 following AZD6738 plus radiation, but no differences were observed at days 9 or 12 (Supplemental Figure 7C).

AZD6738 impacts proliferating splenic and tumor-infiltrating $T$ cells in CT26 tumor-bearing mice. We next examined proliferating $\left(\mathrm{Ki}^{+} \mathrm{7}^{+}\right.$splenic and tumor-infiltrating $\mathrm{T}$ cell populations. At day 5 , radiation alone increased the percentage of splenic $\mathrm{CD} 8{ }^{+} \mathrm{Ki} 67^{+}$ $\mathrm{T}$ cells compared with all other treatments $(11.6 \% \pm 2.7 \%$ radiation vs. $8.9 \% \pm 1.4 \%$ vehicle, $P=0.042$; vs. $7.2 \% \pm 1.2 \%$ AZD 6738 , $P=0.0005$; vs. $8.4 \% \pm 1.2 \%$ AZD 6738 plus radiation, $P=0.012$ ) (Figure 5A). No differences in tumor-infiltrating $\mathrm{CD} 8^{+} \mathrm{K} 67^{+} \mathrm{T}$ cells 
A

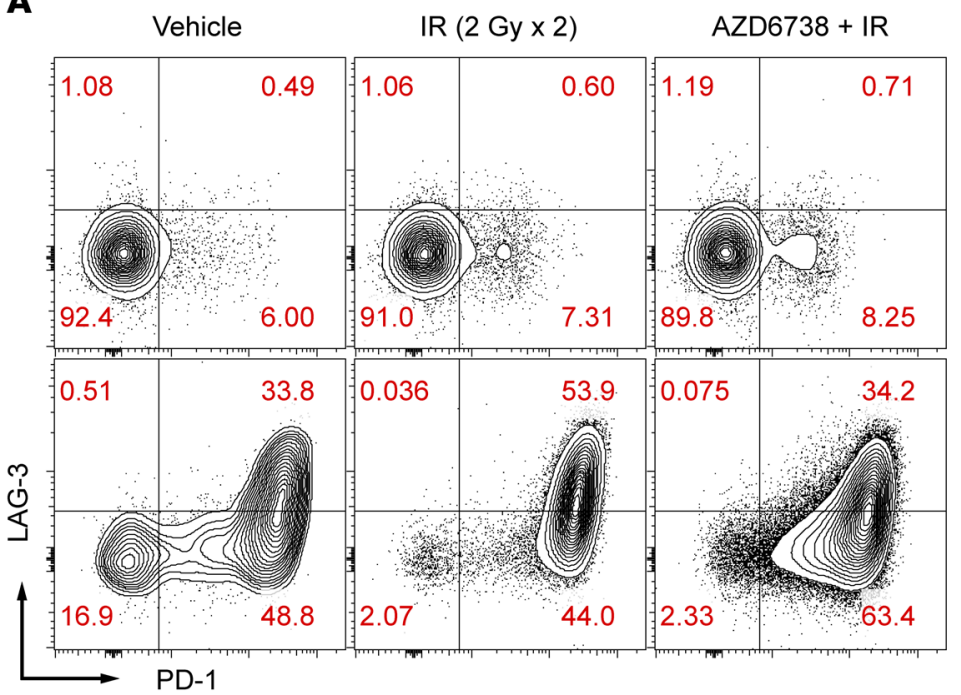

C

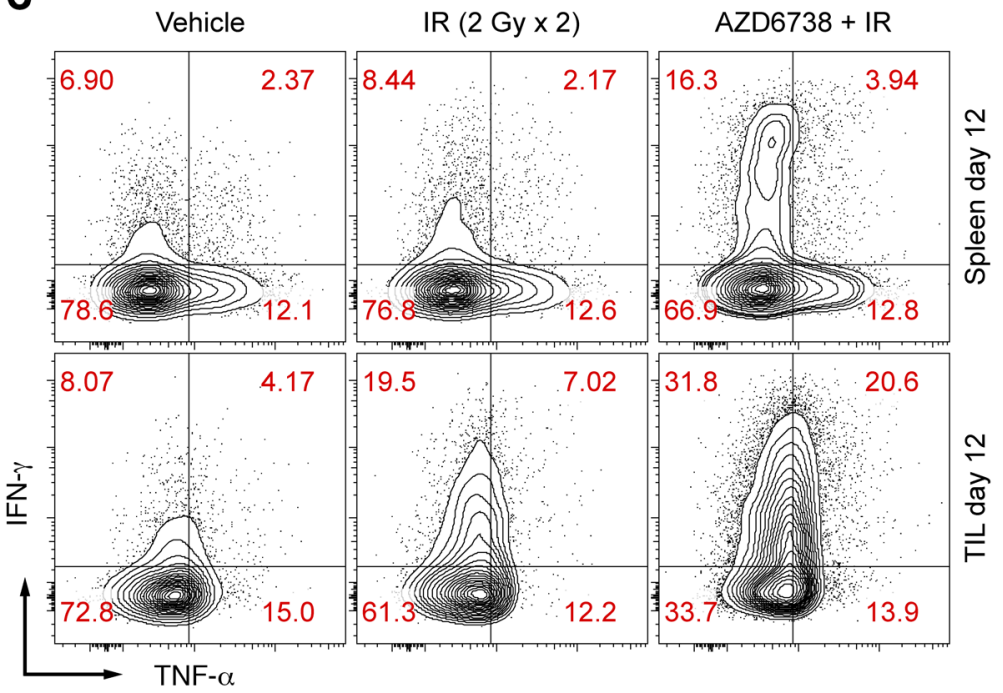

B
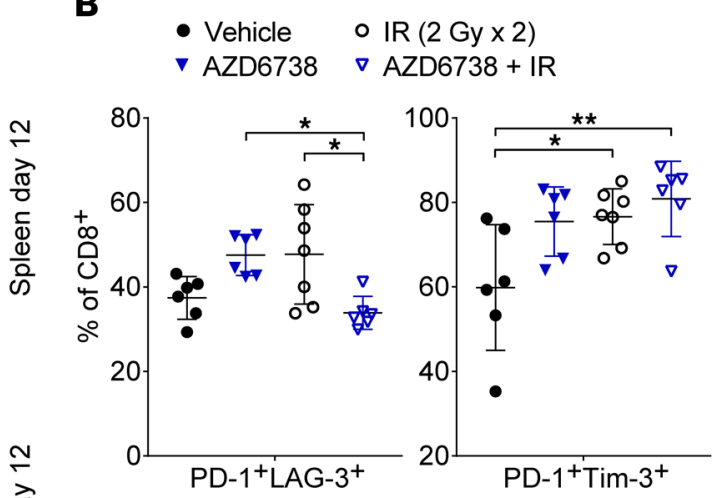

D

- Vehicle $\quad$ IR $(2$ Gy $\times 2)$

v AZD6738 $\nabla$ AZD6738 + IR

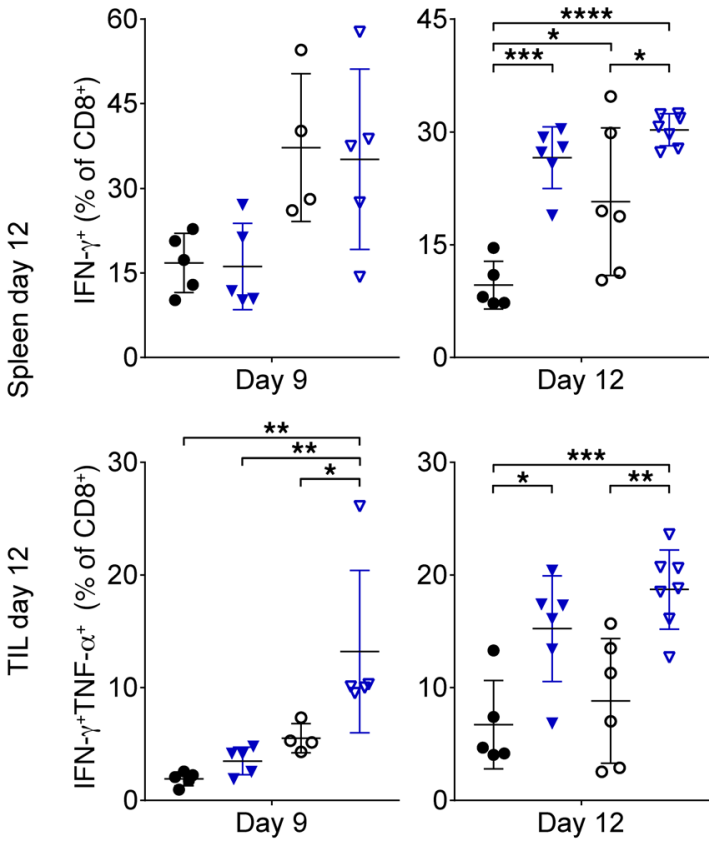

Figure 7. AZD6738 attenuates coexpression of $\mathrm{CD8}^{+} \mathrm{T}$ cell exhaustion markers and promotes $\mathrm{CD8}^{+} \mathrm{T}$ cell effector function in $\mathrm{CT26}$ tumors following radiation. (A) Representative contour plots depicting PD-1 and LAG-3 expression on splenic and tumor-infiltrating (TIL) CD8 ${ }^{+} \mathrm{T}$ cells for the designated treatment groups at day 12. (B) Quantitation of the percentage of TIL CD8 ${ }^{+}$T cells that coexpress PD-1 and LAG-3 or PD-1 and Tim-3 at day 12 . Data from 3 independent experiments per time point, each with 1-3 mice per arm. $n$ at day $12=6$ per arm (7 IR). (C) Representative contour plots depicting IFN- $\gamma$ and TNF- $\alpha$ expression by splenic and tumor-infiltrating (TIL) CD8 ${ }^{+}$T cells for the designated treatment groups following stimulation with PMA/ionomycin at day 12. (D) Quantitation of the percentage of TIL CD8 ${ }^{+}$T cells that elicit IFN- $\gamma$ or IFN- $\gamma$ and TNF- $\alpha$ following stimulation with PMA and ionomycin at days 9 and 12. Day 9 data from 1 experiment with the IR/AZD6738 + IR arms and vehicle/AZD6738 arms staggered and harvested/stained on separate days. $n$ at day $9=5$ per arm (4 IR). Day 12 data from 3 independent experiments, each with 1-3 mice per arm, with harvesting/staining for all arms performed on the same day within a given experiment. $n$ at day $12=5$ vehicle, 6 AZD6738, 6 IR, 7 AZD6738 + IR. (B and D) Mean and SD bars shown. ${ }^{*} P<0.05,{ }^{* *} P<0.01$, ${ }^{* * *} P<0.001,{ }^{* * *} P<0.0001$, ANOVA with Tukey's multiple-comparisons test. Brackets not shown for comparisons that were not statistically significant.

were observed at this time point. At day 9, compared with vehicle control, AZD 6738 plus radiation increased the percentages of both splenic and tumor-infiltrating $\mathrm{CD} 8^{+} \mathrm{Ki} 67^{+} \mathrm{T}$ cells (spleen: $22.9 \% \pm$ $5.4 \%$ AZD 6738 plus radiation vs. $11.5 \% \pm 3.5 \%$ vehicle, $P=0.0095$; tumor: $80.5 \% \pm 6.9 \%$ AZD 6738 plus radiation vs. $68.6 \% \pm 7.6 \%$ vehicle, $P=0.03$ ) (Figure $5 \mathrm{~A}$ ). At day 12 , splenic $\mathrm{CD} 8^{+} \mathrm{Ki} 67^{+} \mathrm{T}$ cells were increased following AZD6738 plus radiation compared with all other treatments $(18.5 \% \pm 4.9 \%$ AZD 6738 plus radiation vs. $8.6 \% \pm 1.2 \%$ vehicle, $P=0.0001$; vs. $10.1 \% \pm 3.3 \%$ AZD $6738, P=$ 0.0008 ; vs. $11.8 \% \pm 2.2 \%$ radiation, $P=0.0053$ ) (Figure 5 , $\mathrm{A}$ and
B). At this time point, tumor-infiltrating $\mathrm{CD} 8^{+} \mathrm{Ki} 67^{+} \mathrm{T}$ cells were reduced in radiation-alone-treated mice compared with mice treated with AZD 6738 or AZD 6738 plus radiation $(63.3 \% \pm 10.9 \%$ radiation vs. $77.9 \% \pm 5.2 \%$ AZD $6738, P=0.014 ;$ vs. $77.9 \% \pm 2.6 \%$ AZD6738 plus radiation, $P=0.014$ ) (Figure 5 , A and $B$ ).

AZD6738 alone and AZD6738 plus radiation reduced the percentage of splenic Ki67 $7^{+}$Tregs at day 5 (spleen: $8.9 \% \pm 1.5 \%$ AZD 6738 vs. $21.2 \% \pm 2.3 \%$ vehicle, $P=0.0001$; and vs. $24.7 \% \pm$ $6.4 \%$ radiation, $P<0.0001 ; 12.4 \% \pm 5.5 \%$ AZD6738 plus radiation vs. vehicle, $P=0.0051$; and vs. radiation, $P=0.0001$ ) (Figure 
A

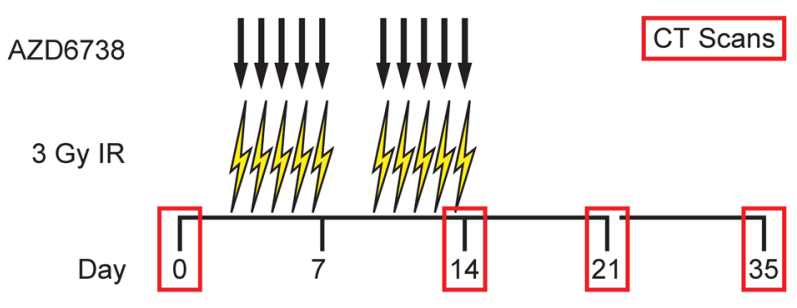

B

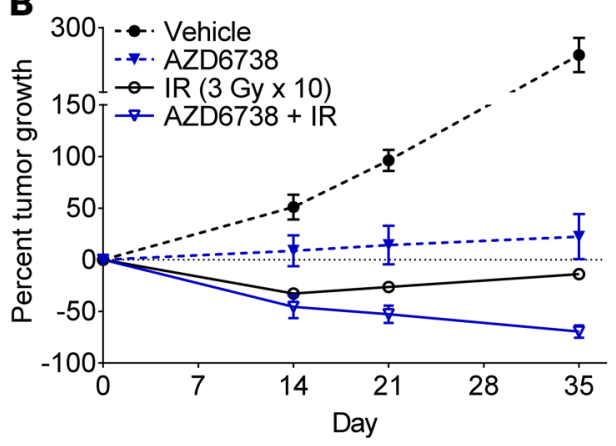

C

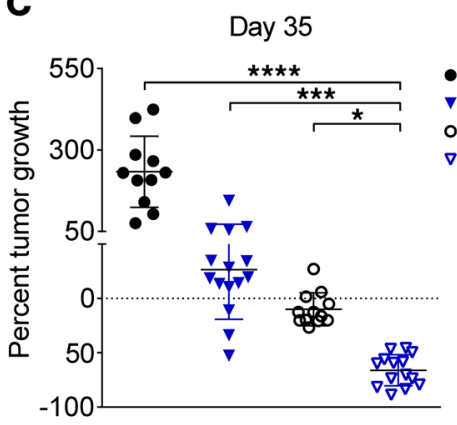

D

- Vehicle

AZD6738

IR $(3$ Gy $\times 10)$
AZD $6738+$ IR

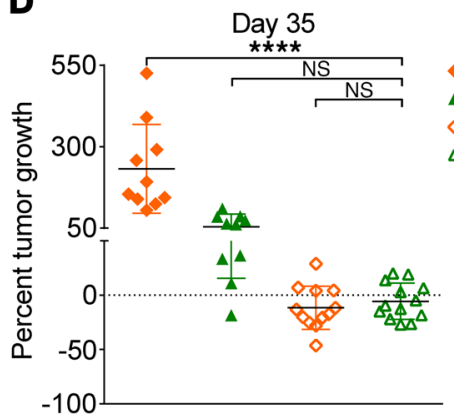

Vehicle + aCD8
AZD6738 + aCD8
IR (3 Gy x 10) + aCD8
$\triangle$ AZD6738 + IR + aCD8
$\mathbf{E}$

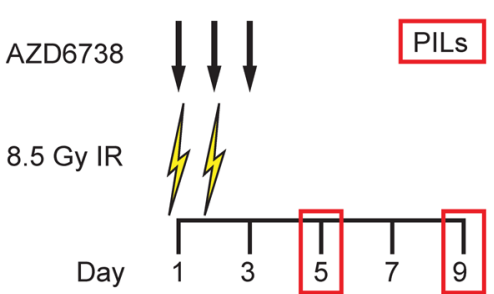

$\mathbf{F}$
G
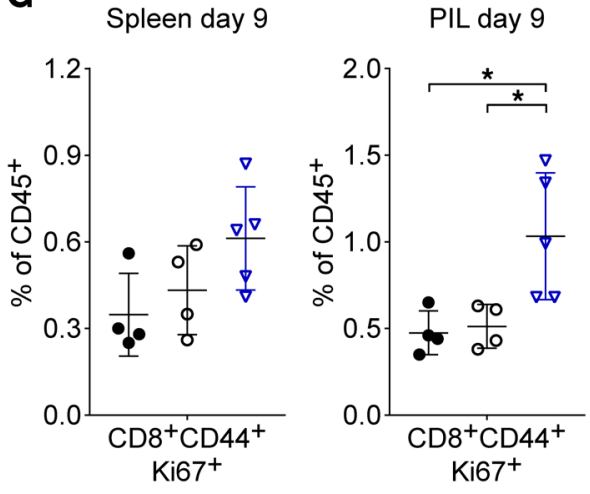

- Untreated o IR (8.5 Gy x 2) $\nabla$ AZD6738 + IR

Figure 8. AZD6738 plus radiation generates a CD8 ${ }^{+} \mathrm{T}$ cell-dependent response in Kras ${ }^{\mathrm{C} 120} /$ Twist 1 lung adenocarcinoma. (A) Schematic showing schedules of hemithoracic radiation (IR), AZD6738, and micro-CT scans. (B) Response of lung tumors over time. Data represent mean percentage tumor volume change from day 0 ( \pm SEM). $n$ (tumors/mice) = 7/3 vehicle, 8/4 AZD6738, 9/4 IR, 7/4 AZD6738 + IR (5/3 day 21). (C) Percent tumor volume change at day 35. $n$ (tumors/mice) $=11 / 5$ vehicle, 15/7 AZD6738, 12/6 IR, 14/8 AZD6738 + IR. (D) Percent tumor volume change at day 35 in CD8-depleted mice (250 $\mu \mathrm{g}$ anti-CD8 antibody $[\alpha C D 8]$ administered days $3,6,10$, and 13). $n$ (tumors/mice) $=10 / 4$ vehicle $+\alpha$ CD8, 10/5 AZD6738 $+\alpha$ CD8, 12/6 IR $+\alpha$ CD8, 13/6 AZD6738 + IR $+\alpha$ CD8. (C and D) Mean and SD bars shown. ${ }^{*} P<0.05$, ${ }^{* * *} P<0.001$, ${ }^{* * *} P<0.0001$, ANOVA with Holm-Šidák multiple-comparisons test. Statistical significance shown only for comparisons with AZD6738 + IR (C) or AZD6738 + $\alpha$ CD8 + IR (D). (E) Schematic showing schedules of hemithoracic IR, AZD6738, and pulmonary-infiltrating lymphocyte (PIL) profiling. (F) Quantitation of splenic and PIL proliferating (Ki67 ) Tregs at day 5 following AZD6738 treatment, compared with untreated control. (C) Quantitation of splenic and PIL proliferating (Ki67+) CD8 ${ }^{+} \mathrm{CD} 44^{+} \mathrm{T}$ cells at day 9 following treatment with IR or AZD6738 plus IR, compared with untreated control. (F and G) Data from 1 (IR/AZD6738 + IR, day 9 only), 2 (AZD6738, day 5 only), or 3 (untreated) independent experiments, with 1-5 mice per arm per experiment. $n=4$ untreated, 5 AZD6738, 4 IR, 5 AZD6738 + IR. Mean and SD bars shown. $(\mathbf{F}){ }^{* *} P<0.01$, unpaired, 2-tailed $t$ test. (G) ${ }^{*} P<0.05$, ANOVA with Tukey's multiple-comparisons test. Brackets not shown for comparisons that were not statistically significant.

5, C and D). Similar effects of AZD6738 alone and AZD6738 plus radiation on tumor-infiltrating $\mathrm{Ki} 7^{+}$Tregs were observed at day 5 $(14.1 \% \pm 2.7 \%$ AZD 6738 vs. $40.3 \% \pm 2.7 \%$ vehicle, $P<0.0001$; and vs. $40.3 \% \pm 4.5 \%$ radiation, $P<0.0001 ; 15.2 \% \pm 3.9 \%$ AZD 6738 plus radiation vs. vehicle, $P<0.0001$; and vs. radiation, $P<$ 0.0001) (Figure 5, C and D). The reverse was observed at day 9, with a greater percentage of tumor-infiltrating Ki67 ${ }^{+}$Tregs following treatment with AZD6738 or AZD6738 plus radiation $(65.3 \%$ $\pm 4.6 \%$ AZD 6738 vs. $45.8 \% \pm 6.7 \%$ vehicle, $P=0.0004$; and vs. $44.6 \% \pm 6.3 \%$ radiation, $P=0.0002 ; 67.1 \% \pm 6.2 \%$ AZD6738 plus radiation vs. vehicle, $P<0.0001$; and vs. radiation, $P<0.0001$ ) (Figure 5D). Differences in splenic Ki67 ${ }^{+}$Tregs at day 9 were not statistically significant, and no differences in splenic or tumorinfiltrating $\mathrm{Ki}^{+} 7^{+}$Tregs were observed at day 12 (Figure 5D and Supplemental Figure 8A). Splenic and tumor-infiltrating $\mathrm{Ki}^{+} \mathrm{7}^{+}$ $\mathrm{CD}^{+}$Eff $\mathrm{T}$ cells exhibited similar trends to Tregs in response to 
AZD6738 alone and AZD6738 plus radiation at each time point, although with reduced magnitude, with the exception that mice treated with AZD6738 plus radiation exhibited an increase in splenic $\mathrm{Ki} 67^{+} \mathrm{CD} 4^{+}$Eff $\mathrm{T}$ cells at day 9 similar to that observed in splenic $\mathrm{CD}^{+} \mathrm{T}$ cells at this time point (Supplemental Figure $8 \mathrm{~B}$ ).

AZD6738 impacts $C D 8^{+} T$ cell activation in CT26 tumor-bearing mice. We determined the activation and memory status of splenic and CT26 tumor-infiltrating $\mathrm{CD}^{+}$and $\mathrm{CD} 4^{+}$Eff T cells. At day 5, AZD6738 alone and AZD6738 plus radiation increased the percentage of splenic $\mathrm{CD} 8^{+}$naive $\mathrm{T}\left(\mathrm{T}_{\mathrm{N}}\right)$ cells compared with vehicle and radiation alone $(67.1 \% \pm 5.0 \%$ AZD 6738 vs. $60.1 \% \pm 3.5 \%$ vehicle, $P=0.011$; and vs. $60.9 \% \pm 3.5 \%$ radiation, $P=0.029$; $66.8 \% \pm 3.1 \%$ AZD 6738 plus radiation vs. vehicle, $P=0.015$; and vs. radiation, $P=0.041$ ) (Figure 6, A and B). In addition, AZD6738 alone and AZD6738 plus radiation reduced the percentage of splenic $\mathrm{CD}^{+}$effector/effector memory $\mathrm{T}\left(\mathrm{T}_{\mathrm{EM}}\right)$ cells at this time point $(5.9 \% \pm 1.0 \%$ AZD 6738 vs. $8.7 \% \pm 1.1 \%$ vehicle, $P=0.0031 ; 5.5 \% \pm$ $1.1 \%$ AZD6738 plus radiation vs. vehicle, $P=0.0008$; and vs. $7.8 \% \pm$ $1.9 \%$ radiation, $P=0.021$ ) (Figure $6, \mathrm{~A}$ and $\mathrm{B}$ ). No significant differences in splenic $\mathrm{CD}^{+}$central memory $\mathrm{T}\left(\mathrm{T}_{\mathrm{CM}}\right)$ cells were observed at day 5. AZD 6738 plus radiation resulted in an increased percentage of tumor-infiltrating $\mathrm{CD}^{+} \mathrm{T}_{\mathrm{CM}}$, but not $\mathrm{T}_{\mathrm{EM}}$, cells compared with vehicle and AZD 6738 alone at day $5(8.0 \% \pm 1.5 \%$ AZD6738 plus radiation $\mathrm{T}_{\mathrm{CM}}$ vs. $4.0 \% \pm 1.9 \%$ vehicle $\mathrm{T}_{\mathrm{CM}}, P=0.0038$; vs. $5.0 \% \pm 1.7 \%$ AZD6738 $\mathrm{T}_{\mathrm{CM}}, P=0.04$ ) (Figure 6, A and C).

At day 9, the percentage of tumor-infiltrating $C D 8^{+} T_{C M}$ cells was reduced following radiation alone relative to AZD6738 plus radiation $\left(1.4 \% \pm 0.6 \%\right.$ radiation $\mathrm{T}_{\mathrm{CM}}$ vs. $4.4 \% \pm 2.1 \%$ AZD 6738 plus radiation $\mathrm{T}_{\mathrm{CM}}, P=0.0027$ ) (Figure $6 \mathrm{C}$ and Supplemental Figure 9A). Radiation resulted in a small but statistically significant reduction in the percentage of tumor-infiltrating $\mathrm{CD}^{+} \mathrm{T}_{\mathrm{EM}}$ cells compared with vehicle and AZD6738 plus radiation $(82.5 \% \pm$ $3.0 \%$ radiation $\mathrm{T}_{\mathrm{EM}}$ vs. $89.5 \% \pm 2.2 \%$ vehicle, $P=0.0022 ; \mathrm{vs.} 87.6 \%$ $\pm 2.7 \%$ AZD6738 plus radiation $\mathrm{T}_{\mathrm{EM}}, P=0.021$ ) (Figure $6 \mathrm{C}$ and Supplemental Figure 9A). However, this reduction in the percentage of tumor-infiltrating $\mathrm{CD} 8^{+} \mathrm{T}_{\mathrm{EM}}$ cells with radiation was associated with reduced CD44 fluorescence intensity and an increased percentage of $\mathrm{CD} 8^{+} \mathrm{T}$ cells with a CD62 $\mathrm{L}^{\mathrm{lo}} \mathrm{CD} 44^{\text {lo }}$ expression phenotype (Supplemental Figure 9, B and C). By day 12, the tumorinfiltrating $\mathrm{CD}^{+} \mathrm{T}$ cells from mice treated with radiation alone and with AZD6738 plus radiation were predominantly of the $T_{\mathrm{EM}}$ phenotype, and no differences were observed between these 2 treatment groups (Supplemental Figure 9D). No differences in splenic $C D 8^{+} \mathrm{T}_{\mathrm{N}}, \mathrm{T}_{\mathrm{CM}}$, or $\mathrm{T}_{\mathrm{EM}}$ cells were observed at day 9, while AZD6738 plus radiation led to reduced splenic $\mathrm{T}_{\mathrm{N}}$ cells and increased splenic CD8 ${ }^{+} \mathrm{T}_{\mathrm{EM}}$ cells at day 12 (Supplemental Figure $9 \mathrm{E})$. No significant differences in activation or memory status of splenic or tumor-infiltrating $\mathrm{CD}^{+} \mathrm{Eff} \mathrm{T}$ cells were observed among treatments at any time point (Supplemental Figure 10, A and B).

Expression of the inhibitory immune checkpoint receptor PD-1 on T cells is induced upon T cell receptor (TCR) ligation, and PD-1 expression marks the activation of antigen-specific $\mathrm{T}$ cells $(42,43)$. We examined expression of PD-1 on tumorinfiltrating $\mathrm{CD}^{+}$and $\mathrm{CD} 4{ }^{+}$Eff $\mathrm{T}$ cells. At day 5, both AZD6738 alone and AZD6738 plus radiation reduced the percentage of tumor-infiltrating $\mathrm{CD} 8^{+} \mathrm{PD}-1^{+} \mathrm{T}$ cells compared with vehicle control $(9.8 \% \pm 4.8 \%$ AZD 6738 vs. $44.8 \% \pm 21.3 \%$ vehicle, $P=0.0016$; and $13.6 \% \pm 9.9 \%$ AZD 6738 plus radiation vs. vehicle, $P=0.005$ ) (Figure $6 \mathrm{D}$ ). At day 9 , radiation alone, but not AZD6738 plus radiation, resulted in a significant increase in tumor-infiltrating $\mathrm{CD}^{+} \mathrm{PD}-1^{+} \mathrm{T}$ cells compared with all other treatment groups $(75.0 \% \pm 7.7 \%$ radiation vs. $49.4 \% \pm$ $16.6 \%$ vehicle, $P=0.022$; and vs. $39.4 \% \pm 13.9 \%$ AZD 6738 , $P=0.0042$; and vs. $41.4 \% \pm 17.6 \%$ AZD 6738 plus radiation, $P=0.0016$ ) (Figure 6D).

At day 12, radiation alone and AZD6738 plus radiation resulted in an increased percentage of tumor-infiltrating CD8 ${ }^{+} \mathrm{PD}-1^{+} \mathrm{T}$ cells compared with vehicle control $(96.7 \% \pm 3.2 \%$ AZD6738 plus radiation vs. $86.6 \% \pm 8.9 \%$ vehicle, $P=0.015$; and $96.9 \% \pm 2.0 \%$ radiation vs. vehicle, $P=0.01$ ) (Supplemental Figure 11A). However, $\mathrm{CD}^{+} \mathrm{T}$ cells from the tumor-infiltrating lymphocytes (TILs) of mice treated with AZD6738 plus radiation exhibited significantly reduced PD-1 MFI compared with all other treatment groups (Supplemental Figure 11B). We also noted reduced PD-1 MFI at day 9 on $\mathrm{CD}^{+} \mathrm{T}$ cells from mice treated with AZD6738 plus radiation compared with vehicle control (Supplemental Figure 11B).

In contrast, AZD6738 alone and AZD6738 plus radiation did not reduce the percentage of tumor-infiltrating, PD-1-expressing $\mathrm{CD} 4^{+}$Eff T cells at day 5 or day 9 (Supplemental Figure 11C). At day 12, AZD6738 plus radiation resulted in an increased percentage of PD $-1^{+} \mathrm{CD} 4^{+}$Eff $\mathrm{T}$ cells compared with vehicle control $(52.1 \% \pm$ $10.6 \%$ AZD 6738 plus radiation vs. $37.8 \% \pm 3.8 \%$ vehicle, $P=0.007$ ) (Supplemental Figure 11C).

AZD6738 attenuates coexpression of $C D 8^{+} T$ cell exhaustion markers in CT26 tumors following radiation. Dysfunctional exhausted $\mathrm{T}$ cells are characterized by the elevated expression of PD-1, LAG-3, and Tim-3 (44-47). Tumor-infiltrating PD-1- and LAG-3-coexpressing $\mathrm{CD}^{+} \mathrm{T}$ cells were significantly reduced in mice treated with AZD6738 plus radiation compared with AZD 6738 alone and radiation alone $(33.9 \% \pm 3.9 \%$ AZD 6738 plus radiation vs. $47.5 \% \pm 4.8 \%$ AZD $6738, P=0.021$; and vs. $47.7 \% \pm$ $11.8 \%$ radiation, $P=0.015$ ) (Figure $7, \mathrm{~A}$ and $\mathrm{B}$ ). In contrast, both radiation alone and AZD6738 plus radiation increased $P D-1-$ and Tim-3-coexpressing CD8 ${ }^{+} \mathrm{T}$ cells compared with vehicle control (Figure 7B and Supplemental Figure 12A). However, we noted significantly reduced PD-1 and Tim-3 MFI on tumor-infiltrating CD8 ${ }^{+} \mathrm{PD}-1^{+}{ }^{-}$im $-3^{+} \mathrm{T}$ cells from mice treated with AZD6738 plus radiation compared with all other groups (Supplemental Figure 12B). Similarly, we noted significantly reduced PD-1 MFI on tumor-infiltrating $\mathrm{CD} 8^{+} \mathrm{PD}-1^{+} \mathrm{LAG}-3^{+} \mathrm{T}$ cells following AZD6738 plus radiation treatment compared with all other treatments (Supplemental Figure 12C).

In contrast, while a smaller overall proportion of tumorinfiltrating $\mathrm{CD}^{+}{ }^{+}$Eff $\mathrm{T}$ cells coexpressed PD- 1 and LAG-3 (as compared with tumor-infiltrating $\mathrm{CD} 8^{+} \mathrm{T}$ cells), $\mathrm{PD}-1^{+} \mathrm{LAG}-3^{+} \mathrm{CD} 4^{+}$ Eff $\mathrm{T}$ cells were increased in the tumors treated with AZD6738 alone and with AZD 6738 plus radiation $(7.9 \% \pm 2.3 \%$ AZD 6738 vs. $2.5 \% \pm 0.7 \%$ vehicle, $P=0.0001$; and vs. $5.1 \% \pm 2.1 \%$ radiation, $P=$ $0.035 ; 7.1 \% \pm 1.1 \%$ AZD 6738 plus radiation vs. vehicle, $P=0.0006$ ) (Supplemental Figure 12D). Tumor-infiltrating PD-1- and Tim3-coexpressing CD4+ Eff T cells were also increased following treatment with AZD6738 alone or AZD6738 plus radiation compared with treatment with vehicle control $(10.4 \% \pm 4.1 \%$ AZD 6738 
vs. $3.9 \% \pm 0.7 \%$ vehicle, $P=0.029 ; 16.1 \% \pm 5.1 \%$ AZD 6738 plus radiation vs. vehicle, $P<0.0001$; and vs. $8.9 \% \pm 3.6 \%$ radiation, $P=0.013$ ) (Supplemental Figure 12B).

AZD6738 promotes $C D 8^{+} T$ cell effector function in $C T 26$ tumors following radiation. We determined whether the effects of AZD6738 plus radiation on $\mathrm{CD}^{+} \mathrm{T}$ cell activation and coexpression of exhaustion markers correlated with increased effector function at the later time points by examining production of IFN- $\gamma$, TNF- $\alpha$, and IL-2 following stimulation with PMA and ionomycin at days 9 and 12 (Figure 7, C and D, and Supplemental Figure $13 \mathrm{~A})$. Both radiation alone and AZD6738 plus radiation increased the percentage of tumor-infiltrating $\mathrm{CD}^{+} \mathrm{T}$ cells that produced IFN- $\gamma$ alone at day 9, but these differences did not reach statistical significance (Figure 7D). In contrast, AZD6738 plus radiation increased the percentage of tumor-infiltrating $\mathrm{CD}^{+} \mathrm{T}$ cells that coproduced both IFN- $\gamma$ and TNF- $\alpha$ (13.2\% $\pm 7.2 \%$ AZD6738 plus radiation vs. $1.9 \% \pm 0.6 \%$ vehicle, $P=0.0016$; and vs. $3.5 \% \pm 1.2 \%$ AZD6738, $P=0.0057$; and vs. $5.5 \% \pm 1.3 \%$ radiation, $P=0.041$ ) (Figure 7D). In addition, IL-2 production (measured as fold change in MFI over unstimulated spleen control) was increased following AZD6738 plus radiation compared with AZD6738 alone or vehicle control (2.6-fold \pm 0.7-fold AZD6738 plus radiation vs. 1.6-fold \pm 0.2-fold AZD6738, $P=0.006$; and vs. 1.6-fold \pm 0.2 -fold vehicle, $P=0.0061$ ) (Supplemental Figure 13A). At day 12, the effects of AZD6738 plus radiation on $\mathrm{CD}^{+} \mathrm{T}$ cell effector function were more striking. While production of IFN- $\gamma$ alone was increased among all treatments compared with vehicle control $(30.3 \% \pm$ 2.1\% AZD6738 plus radiation vs. 9.6\% $\pm 3.2 \%$ vehicle, $P<0.0001$; $26.6 \% \pm 4.1 \%$ AZD 6738 vs. vehicle, $P=0.0004$; and $20.8 \% \pm 9.8 \%$ radiation, $P=0.019)$, AZD6738 plus radiation also significantly increased the percentage of tumor-infiltrating $\mathrm{CD}^{+} \mathrm{T}$ cells that produced IFN- $\gamma$ alone compared with radiation alone (AZD6738 plus radiation vs. radiation, $P=0.03$ ) (Figure 7, $C$ and D). Moreover, while AZD6738 alone and AZD6738 plus radiation increased coproduction of IFN- $\gamma$ and TNF- $\alpha$ by the tumor-infiltrating CD8 ${ }^{+}$ $\mathrm{T}$ cells compared with vehicle control $(15.2 \% \pm 4.7 \%$ AZD6738 vs. $6.7 \% \pm 3.9 \%$ vehicle, $P=0.024 ; 18.7 \% \pm 3.5 \%$ AZD6738 plus radiation vs. vehicle, $P=0.001$ ), only AZD6738 plus radiation resulted in increased coproduction of IFN- $\gamma$ and TNF- $\alpha$ compared with radiation alone (AZD6738 plus radiation vs. 8.8\% $\pm 5.5 \%$ radiation, $P=0.0038$ ) (Figure 7, C and D). As at day 9, IL-2 production was increased following AZD6738 plus radiation compared with vehicle control (2.2-fold \pm 0.2 -fold AZD6738 plus radiation vs. 1.6fold \pm 0.4 -fold vehicle, $P=0.026$ ) (Supplemental Figure 13A). Taken together, these data support that treatment with AZD6738 plus radiation promotes increased $\mathrm{CD} 8^{+} \mathrm{T}$ cell effector function at the later time points compared with treatment with radiation alone.

In stimulated $\mathrm{CD}^{+}$Eff $\mathrm{T}$ cells, radiation alone and AZD6738 plus radiation both increased coproduction of IFN- $\gamma$ and TNF- $\alpha$ at day $9(5.2 \% \pm 1.2 \%$ radiation vs. $0.9 \% \pm 0.2 \%$ vehicle, $P=$ 0.037 ; and $7.7 \% \pm 3.9 \%$ AZD6738 plus radiation vs. vehicle, $P=$ 0.0007; and AZD6738 plus radiation vs. $1.6 \% \pm 0.5 \%$ AZD6738, $P=0.0016$ ) (Supplemental Figure 13B). IL-2 was significantly increased following only AZD6738 plus radiation compared with AZD6738 alone and vehicle control (2.6-fold \pm 0.5 -fold AZD6738 plus radiation vs. 1.9 -fold \pm 0.4 -fold AZD6738, $P=$ 0.42 ; vs. 1.3 -fold \pm 0.2 -fold vehicle, $P=0.0004$ ) (Supplemental
Figure 13, B and C). No significant differences in IFN- $\gamma$ production, IFN- $\gamma$ and TNF- $\alpha$ coproduction, or IL- 2 production by tumorinfiltrating $\mathrm{CD}^{+}$Eff $\mathrm{T}$ cells were observed among treatments at day 12 (Supplemental Figure 13, B and C).

AZD6738 plus radiation generates a $C D 8^{+} T$ cell-dependent response in a GEMM of lung adenocarcinoma. We evaluated the impact of AZD6738 on radiation in a GEMM of Kras ${ }^{\text {G12D }} /$ Twist1driven, luciferase-expressing lung adenocarcinoma (48). We treated mice with AZD $6738(75 \mathrm{mg} / \mathrm{kg})$ approximately 90 minutes prior to $3 \mathrm{~Gy}$ of hemithoracic radiation (IR) on days 3-7 and 10-14 ( 5 days on, 2 days off, 5 days on) (Figure 8A). The dose and schedule of radiation were selected to mimic a clinically relevant hyperfractionated dosing schedule used in the treatment of non-small cell lung cancer. Micro-CT scans on day 0 were used to stratify mice into treatment groups and to quantify response (measured as the percentage change in tumor volume from day 0) on days 14, 21, and 35 (Figure 8A and Supplemental Figure 14A).

Radiation treatment groups exhibited mean tumor regression, while mock radiation treatment groups exhibited mean tumor growth (Figure 8, B and C, and Supplemental Figure 14, B and C). At day 14, radiation alone and AZD6738 plus radiation resulted in similar tumor regression (mean \pm SD: $32.7 \% \pm 12.9 \%$ regression radiation vs. $45.6 \% \pm 29.1 \%$ regression AZD 6738 plus radiation, $P=0.41$ ) (Supplemental Figure 14C). At day 35, AD6738 resulted in significantly greater tumor regression than radiation alone $(66.2 \% \pm 14.4 \%$ regression AZD6738 plus radiation vs. $9.9 \% \pm$ $15.2 \%$ regression radiation, $P=0.03$ ) (Figure $8 C$ ). While AZD6738 alone reduced tumor growth compared with vehicle control at day $35(26.6 \% \pm 45.7 \%$ growth AZD6738 vs. $233.4 \% \pm 109.2 \%$ growth vehicle, $P<0.0001$ ), AZD6738 plus radiation resulted in a significantly greater antitumor response than AZD6738 alone $(P=0.0002)$ (Figure 8C).

We observed continued tumor regression from the end of treatment (day 14) until day 35 in mice treated with AZD6738 plus radiation, while mice treated with radiation alone exhibited tumor regrowth during this time. As the delayed impact of AZD6738 on radiation is similar to that observed in the syngeneic CT26 model, and is consistent with the delayed impact of anti-PD-L1 therapy on radiation $(9,19,22)$, we hypothesized that the response to AZD6738 plus radiation is $\mathrm{CD} 8^{+} \mathrm{T}$ cell dependent. Depletion of $\mathrm{CD}^{+} \mathrm{T}$ cells in the GEMM of lung adenocarcinoma did not abolish the efficacy of AZD 6738 alone or radiation alone $(54.3 \% \pm 38.8 \%$ growth AZD6738 plus anti-CD8 vs. $232.4 \% \pm 136.2 \%$ growth vehicle plus anti-CD8, $P<0.0001 ; 11.5 \% \pm 19.9 \%$ regression radiation plus anti-CD8 vs. growth vehicle plus anti-CD8, $P<0.0001)$. However, in CD8-depleted mice, AZD6738 plus radiation provided no benefit over radiation alone or AZD6738 alone $(5.6 \% \pm 16.7 \%$ regression AZD6738 plus radiation plus anti-CD8 vs. regression radiation plus anti-CD8, $P=0.83$; and vs. growth AZD6738 plus anti-CD8, $P=0.084$ ) (Figure $8 D$ ). Therefore, AZD6738 plus a clinically relevant fractionated schedule of radiation induces a $\mathrm{CD}^{+} \mathrm{T}$ cell-dependent antitumor immune response in a GEMM of $\mathrm{Kras}^{\mathrm{G12D}} /$ Twist1-driven lung adenocarcinoma.

As a proof of concept, we sought to demonstrate that AZD6738 treatment modulates pulmonary-infiltrating lymphocytes (PILs) in mice bearing Kras ${ }^{G 12 D} /$ Twist1 lung tumors. During the course of our work, Herter-Sprie et al. demonstrated synergy of PD-1 
blockade with two 8.5-Gy fractions of targeted radiation in a GEMM of $\mathrm{Kras}^{\mathrm{G12}}$-driven lung adenocarcinoma (22). Therefore, we treated mice with 8.5-Gy fractions of hemithoracic radiation (right lung) on days 1-2 and AZD6738 (75 mg/kg) on days 1-3 (Figure 8E). Because of limitations in available $\mathrm{Kras}^{\mathrm{G12D}} /$ Twist1 tumorbearing mice, AZD6738 alone was evaluated only at day 5, and radiation alone and AZD6738 plus radiation were evaluated only at day 9. A cohort of untreated control mice was used for comparisons with treatment arms at both time points.

At day 5, AZD6738 alone did not result in significant differences in PIL CD45 immune cells, activated $\mathrm{CD}^{+}\left(\mathrm{CD} 8^{+} \mathrm{CD} 44^{+}\right)$ $\mathrm{T}$ cells, Tregs, or activated $\mathrm{CD} 4^{+}$effector $\left(\mathrm{CD} 4^{+} \mathrm{CD} 44^{+}\right.$Eff) $\mathrm{T}$ cells, compared with untreated control (Supplemental Figure $15, \mathrm{~A}$ and $\mathrm{B})$. We also observed no significant differences in the $\mathrm{CD}^{+} \mathrm{CD} 44^{+} /$Treg or $\mathrm{CD} 4{ }^{+} \mathrm{CD} 44^{+}$Eff/Treg ratios among PIL $\mathrm{T}$ cells (Supplemental Figure 15C). However, as observed in the syngeneic CT26 model, AZD6738 treatment alone resulted in significant reductions in both the splenic and PIL proliferating $\left(\mathrm{Ki}^{+} \mathrm{7}^{+}\right.$) Treg populations (as a percentage of CD $45^{+}$immune cells) in $\mathrm{Kras}^{\mathrm{G12D}} /$ Twist1 tumor-bearing mice (spleen, $0.12 \% \pm 0.03 \%$ AZD 6738 vs. $0.50 \% \pm 0.17 \%$ untreated control, $P=0.0013$; PIL, $0.26 \% \pm 0.10 \%$ AZD 6738 vs. $1.05 \% \pm 0.39 \%$ untreated control, $P=0.0033$ ) (Figure 8F). AZD6738 treatment alone also significantly reduced splenic and PIL proliferating CD $8{ }^{+} \mathrm{CD} 44^{+} \mathrm{T}$ cells (spleen, $0.15 \% \pm 0.03 \%$ AZD 6738 vs. $0.35 \% \pm 0.14 \%$ untreated control, $P=0.019$; PIL, $0.24 \% \pm 0.07 \%$ AZD6738 vs. $0.48 \% \pm$ $0.13 \%$ untreated control, $P=0.0086)$ and $C D 4^{+} \mathrm{CD} 44^{+}$Eff $\mathrm{T}$ cells (spleen, $1.5 \% \pm 0.2 \%$ AZD 6738 vs. $2.4 \% \pm 0.7 \%$ untreated control, $P=0.03$; PIL, $2.5 \% \pm 0.4 \%$ AZD 6738 vs. $4.0 \% \pm 1.3 \%$ untreated control, $P=0.04$ ) (Supplemental Figure 15, D and E).

At day 9, neither radiation alone nor AZD6738 plus radiation resulted in significant differences in PIL CD $45^{+}$immune cells, activated $\mathrm{CD}^{+}\left(\mathrm{CD}^{+} \mathrm{CD} 44^{+}\right) \mathrm{T}$ cells, Tregs, or activated $\mathrm{CD} 4^{+}$ effector $\left(\mathrm{CD} 4^{+} \mathrm{CD} 44^{+} \mathrm{Eff}\right) \mathrm{T}$ cells, compared with untreated control (Supplemental Figure 16, A and B). However, AZD6738 plus radiation increased the percentage of PIL CD $4{ }^{+} \mathrm{CD} 44^{+}$Eff T cells compared with radiation alone $(14.6 \% \pm 1.5 \%$ AZD 6738 plus radiation vs. $10.9 \% \pm 1.7 \%$ radiation, $P=0.0097$ ) (Supplemental Figure 16B). While we observed no significant differences in the PIL $\mathrm{CD}^{+} \mathrm{CD} 44^{+} /$Treg ratio with either treatment, radiation alone, but not AZD6738 plus radiation, resulted in a significant decrease in the $\mathrm{CD} 4{ }^{+} \mathrm{CD} 44^{+}$Eff/Treg ratio compared with untreated control (3.5 \pm 1.3 radiation vs. $6.1 \pm 1.2$ untreated control, $P=0.013)$ (Supplemental Figure 16C).

We also examined proliferating $\left(\mathrm{Ki}^{\circ} 7^{+}\right) \mathrm{T}$ cell populations in the spleen and PILs at day 9. AZD6738 plus radiation treatment resulted in a statistically significant increase in splenic, but not PIL, Ki67 ${ }^{+}$Tregs compared with untreated control (spleen, $0.85 \%$ $\pm 0.09 \%$ AZD 6738 plus radiation vs. $0.50 \% \pm 0.17 \%$ untreated control, $P=0.0051$ ) (Supplemental Figure 16D). No significant differences among treatments were observed in splenic or PIL proliferating $\mathrm{CD} 4{ }^{+} \mathrm{CD} 44^{+}$Eff $\mathrm{T}$ cell populations at this time point (Supplemental Figure 16E). Importantly, treatment with AZD6738 plus radiation led to a significant increase in PIL, but not splenic, proliferating $\mathrm{CD} 8^{+} \mathrm{CD} 44^{+} \mathrm{T}$ cells compared with both radiation alone and untreated control (PIL, 1.03\% $\pm 0.37 \%$ AZD6738 plus radiation vs. $0.51 \% \pm 0.13 \%$ radiation vs. vehicle, $P=0.029$; and vs.
$0.48 \% \pm 0.13 \%$ untreated control, $P=0.02$ ) (Figure $8 G$ ). Lastly, we examined expression of the inhibitory receptors PD-1, LAG-3, and Tim-3 on PIL CD $8{ }^{+}$CD $44^{+}$T cells. LAG-3 expression was largely absent from PIL CD $8{ }^{+} \mathrm{CD} 44^{+} \mathrm{T}$ cells, and therefore was not quantitated. AZD6738 plus radiation resulted in a modest but not statistically significant increase in $\mathrm{PD}-1$-expressing $\mathrm{CD} 8^{+} \mathrm{CD} 44^{+} \mathrm{T}$ cells (Supplemental Figure 16F). This modest increase is unsurprising as expression of $\mathrm{PD}-1$, though an inhibitory receptor, also indicates $\mathrm{T}$ cell activation $(42,43)$, and the observed increase in proliferating $\mathrm{CD} 8^{+} \mathrm{CD} 44^{+} \mathrm{Ki} 67^{+} \mathrm{T}$ cells is consistent with an increase in activated $\mathrm{CD}^{+} \mathrm{T}$ cells. Importantly, AZD6738 plus radiation did not increase PD-1- and Tim-3-coexpressing CD8 ${ }^{+} \mathrm{CD} 44^{+} \mathrm{T}$ cells (Supplemental Figure 16F).

\section{Discussion}

The ATR kinase inhibitor AZD6738 combines with conformal radiation therapy to generate durable, $\mathrm{CD} 8^{+} \mathrm{T}$ cell-dependent antitumor responses in both a syngeneic mouse model and a GEMM of Kras-mutant cancers. In the syngeneic CT26 model, CD8 ${ }^{+} \mathrm{T}$ cell-independent mechanisms likely also contribute to the overall antitumor response, as we observed a strong trend toward greater tumor growth inhibition with AZD6738 plus radiation compared with radiation alone $(P=0.054)$ in the CD8-depleted mice (Figure 2B). However, our data clearly demonstrate that $\mathrm{CD}^{+} \mathrm{T}$ cells are required for maximal efficacy of AZD6738 plus radiation in CT26 tumors. The antitumor responses in the syngeneic CT26 model are associated with attenuation of radiation-induced $\mathrm{CD} 8^{+} \mathrm{T}$ cell exhaustion and potentiation of $\mathrm{CD}^{+} \mathrm{T}$ cell activity in the tumor microenvironment following radiation. Moreover, AZD6738 combines with radiation to generate immunologic memory in complete responder mice in the syngeneic CT26 model. These findings are unexpected and important.

One mechanism through which AZD6738 likely impacts $\mathrm{CD}^{+} \mathrm{T}$ cell-dependent immune responses following radiation is immune checkpoint disruption. AZD6738 attenuated radiationinduced PD-L1 expression on CT26 cells at day 5, and this likely contributes to the augmented $\mathrm{CD}^{+} \mathrm{T}$ cell-dependent antitumor responses that manifest later. AZD6738 attenuated cell-intrinsic radiation-induced PD-L1 upregulation on CT26 cells in vitro, and this is consistent with recently published human cancer cell line data (40). In addition, AZD6738 transiently reduced IFN- $\gamma$ competent $\mathrm{CD}^{+} \mathrm{T}$ cells in the tumor microenvironment at day 5 , likely attenuating IFN- $\gamma$-driven adaptive upregulation of PD-L1 following radiation $(8,9,19)$. We noted that AZD6738 treatment led to increased naive and decreased effector/effector memory splenic CD8 ${ }^{+} \mathrm{T}$ cells, as well as reduced the percentage of tumor-infiltrating $\mathrm{CD}^{+} \mathrm{PD}-1^{+} \mathrm{T}$ cells, at day 5. Collectively, these data suggest that AZD6738 causes a transient reduction in activated $\mathrm{CD} 8^{+} \mathrm{T}$ cells, which likely explains the reduction in tumor-infiltrating, IFN- $\gamma$-competent $C D 8^{+} \mathrm{T}$ cells at day 5 .

AZD6738 plus radiation led to an increase in proliferating tumor-infiltrating CD8 ${ }^{+} \mathrm{T}$ cells in CT26, as well as an increase in proliferating pulmonary infiltrating $\mathrm{CD}^{+} \mathrm{T}$ cells in the GEMM, at day 9. In CT26, this was followed by increased numbers of tumor-infiltrating $\mathrm{CD} 8^{+} \mathrm{T}$ cells at day 12. Importantly, AZD6738 suppressed radiation-induced coexpression of $\mathrm{T}$ cell exhaustion markers in CT26 at day 12 and significantly increased IFN- $\gamma$ and 
TNF- $\alpha$ coproduction at days 9 and 12, as well as production of IFN- $\gamma$ alone at day 12 , signifying that AZD6738 plus radiation promotes an increase in functional tumor-infiltrating $\mathrm{CD}^{+} \mathrm{T}$ cells at these later time points. We were unable to evaluate PD-L1 changes in the GEMM. We also did not observe evidence of radiation-induced $\mathrm{T}$ cell exhaustion in the GEMM. This is likely a function of the low immunogenicity of GEMMs compared with syngeneic models, as well as the abbreviated radiation regimen used for our immune profiling experiments. While it is unclear whether our mechanistic findings of immune checkpoint disruption in the syngeneic CT26 model extend to the GEMM, the $\mathrm{CD}^{+}$-dependent antitumor responses achieved with AZD6738 combined with a hyperfractionated, clinically relevant radiation regimen in the GEMM are consistent with the potentiation of $\mathrm{CD}^{+}$activity in the tumor microenvironment by AZD6738 following radiation.

$\mathrm{CD}^{+} \mathrm{T}$ cell-produced IFN- $\gamma$ is known to drive upregulation of PD-L1 in CT26 tumors (19), and consistent with this, we observed elevated CT26 tumor PD-L1 expression at day 9 following treatment with AZD6738 plus radiation. This indicates that $\mathrm{T}$ cellmediated cytokine signaling in the tumor microenvironment can subsequently drive tumor cell PD-L1 upregulation in the absence of ATR kinase inhibition, and provides the rationale for the use of sequential PD-1 blockade after AZD6738 treatment to preserve T cell function and prevent PD-1/PD-L1-mediated T cell suppression. As PD-1 ligation is not required for the development of $\mathrm{T}$ cell exhaustion, the decreased development of exhausted $\mathrm{T}$ cells may be occurring through means independent of the reduction of tumor PD-L1 expression, further implicating a role for this combination in immune potentiation (49).

A second mechanism through which AZD6738 likely impacts $\mathrm{CD}^{+} \mathrm{T}$ cell-dependent immune responses is by decreasing tumor-infiltrating Tregs. At day 5, AZD6738 alone as well as AZD6738 plus radiation reduced both total and proliferating Tregs in CT26 tumors, but only modestly reduced total CD8 ${ }^{+}$ $\mathrm{T}$ cells while not altering the percentage of proliferating $\mathrm{CD} 8^{+} \mathrm{T}$ cells. Expectedly, the suppression of Tregs following AZD6738 exposure was transient, and proliferating Tregs were increased at day 9 in tumors treated with AZD6738 alone and with AZD6738 plus radiation, while Treg numbers increased to levels comparable with those in tumors treated with radiation alone. Despite this, AZD6738 plus radiation resulted in elevated $\mathrm{CD}^{+} /$Treg ratios relative to vehicle control at each time point, accompanied by increases in total and/or proliferating $\mathrm{CD} 8^{+} \mathrm{T}$ cells at the later time points. This persistent positive $\mathrm{CD}^{+}$-to-Treg balance likely promotes increased activity of infiltrating $\mathrm{CD}^{+} \mathrm{T}$ cells in the tumor microenvironment. Suppression of proliferating Tregs by AZD6738 also was evident in the spleens of CT26 tumor-bearing mice and the spleens and pulmonary infiltrate of $\mathrm{Kras}^{\mathrm{G12D}} / \mathrm{Twist1}$ tumor-bearing mice, indicating that these effects of AZD6738 are systemic and not specific to the TILs. Our observations are important as neoadjuvant treatment with AZD6738 may decrease the number of Tregs in cancer therapy.

It is currently unclear whether AZD6738 impairs the proliferation of Tregs or selectively kills existing proliferating Tregs. Similarly, it is unclear why AZD6738 reduced activated $\mathrm{CD} 8^{+} \mathrm{T}$ cells at the early time point in the CT26 model. A recent report demon- strated that activated $\mathrm{CD} 8^{+} \mathrm{T}$ cells are more susceptible to killing by WEE1 and Chk1/2 inhibition, although the effects were more substantial in vitro than in vivo (50). As Chk1 is a direct target of ATR, it may be that AZD6738 selectively kills recently activated, and still rapidly dividing, $\mathrm{CD}^{+} \mathrm{T}$ cells. Alternatively, AZD6738 may transiently impair activation or clonal expansion of $\mathrm{CD}^{+} \mathrm{T}$ cells by AZD6738. In either case, AZD6738 may effectively delay the adaptive immune response following radiation, which, in turn, is associated with improved $\mathrm{CD}^{+} \mathrm{T}$ cell activity and antitumor responses at later time points.

The clinical significance of our findings is high, as 10 clinical trials of the ATR kinase inhibitor AZD6738 in combination with either chemotherapy or radiation are currently enrolling patients (36). These trials were designed to test hypotheses that ATR kinase inhibitors potentiate DNA-damaging chemotherapy and radiation $(34,38)$. While it is currently unknown whether our findings will extend beyond Kras-mutant cancers, our work raises the exciting possibility that AZD6738 plus radiation may enhance antitumor immune responses leading to immunologic memory and lasting antitumor immunity.

\section{Methods}

Supplemental Methods are available online with this article; https:// doi.org/10.1172/JCI96519DS1.

Cell lines and reagents. CT26 cells were purchased from ATCC. AZD6738 was provided by AstraZeneca and dosed by oral gavage as previously described $(34,38)$. Anti-CD8 antibody ( $\alpha$ CD8, clone YTS 169.4, BioXCell) was diluted in $1 \times$ PBS and administered i.p. (100 $\mu$ l volume).

Mice and treatments. Female BALB/c and athymic nude mice (6-8 weeks old) were purchased from The Jackson Laboratory and Envigo, respectively. CT26 cells $\left(5 \times 10^{5}\right)$ in RPMI were injected s.c. into the right hind flank or, for tumor rechallenge, into the contralateral (left) hind flank of complete responder and tumor-naive BALB/c mice. Treatment was initiated once tumors reached approximately 60-90 $\mathrm{mm}^{3}$ (response experiments) or $90-150 \mathrm{~mm}^{3}$ (TIL experiments). Mice received 2 fractions of $2 \mathrm{~Gy}$ ( $6 \mathrm{mV}$ photon energy, $2 \mathrm{~cm}$ field) on days 1-2. For CD8 depletion, $\alpha \mathrm{CD} 8(250 \mu \mathrm{g})$ was administered on days 1-2. Tumors were measured twice weekly with calipers, and volumes calculated as volume $=\left(\right.$ length $\times$ width $\left.^{2}\right) / 2$. The response endpoint was designated as the day in which more than 1 tumor within a given treatment group reached $1,000 \mathrm{~mm}^{3}$, and the endpoint day for a given treatment group was retained in repeat experiments. The change in tumor volume was calculated as ( $\mathrm{Tf}-\mathrm{Ti}$ ), where $\mathrm{Tf}$ is the final tumor volume at a given time point and $\mathrm{Ti}$ is the tumor volume at day 1 . Mean tumor growth inhibition (TGI) was calculated as TGI $=(1-$ (mean Tf - mean $\mathrm{Ti}) /($ mean $\mathrm{Cf}-$ mean Ci) $\times 100$, where $\mathrm{Tf}$ and $\mathrm{Cf}$ represent the final tumor volumes of treatment and control arms, respectively, and Ti and Ci represent the initial tumor volumes of treatment and control arms, respectively. For calculation of TGI for AZD6738 plus radiation versus radiation alone, radiation alone was treated as the control ( $\mathrm{Cf}$ and $\mathrm{Ci}$ ).

Male and female transgenic FVB/N mice with ras $^{G 12 D} /$ Twist1 (CCSP-rtTA/tetO-Kras ${ }^{G 12 D} /$ Twist1-tet $O_{7}$-luc) lung adenocarcinoma were generated as previously described (48). Doxycycline $(2 \mathrm{mg} / \mathrm{ml})$ drinking water was administered for the duration of the studies. For CD8 depletion, $\alpha$ CD8 (250 $\mu$ g) was administered on days 3, 6, 10, and 13. Imaging and irradiation were performed using a Small Animal Radiation Research Platform (SARRP, Xstrahl). All micro-CT images were 
quantified by a board-certified radiation oncologist (Phuoc Tran), and the percentage tumor volume growth was determined for 1-3 tumors per mouse (48). For pulmonary-infiltrating lymphocyte (PIL) analyses, Kras ${ }^{G 12 D} /$ Twist1 mice received two 8.5-Gy fractions of hemithoracic (right lung) radiation ( $6 \mathrm{mV}$ photon energy) in a customized field (Varian Medical Systems Inc.). At day 5 (AZD6738 alone) or day 9 (radiation and AZD6738 plus radiation), mice were euthanized and perfused with $1 \times$ PBS via the left ventricle, and lungs and spleens were harvested. For irradiated mice, only the irradiated right lung cranial, middle, and caudal lobes were collected. One group of untreated control mice was compared with treatment cohorts at both time points.

Tumor PD-L1 and TIL analyses by flow cytometry. Spleens and CT26 tumors or Kras ${ }^{G 12 D} /$ Twist1 lungs were harvested into RPMI/10\% FBS at the specified time points. Spleens were mechanically dissociated between frosted glass slides. Tumors and lungs were injected with 1.5-2 $\mathrm{ml}$ digestion solution consisting of $50 \mu \mathrm{g} / \mathrm{ml}$ Liberase DL research grade (Roche) and $10 \mathrm{U} / \mathrm{ml}$ DNase I (Sigma) in RPMI. Tissues were incubated 3-5 minutes at room temperature, chopped into small pieces, incubated in a total volume of $5 \mathrm{ml}$ digestion solution for 15 minutes at $37^{\circ} \mathrm{C}$, dissociated between frosted glass slides, and filtered through $70-\mu \mathrm{m}$ cell strainers (Corning) to generate single-cell suspensions. Red blood cells were lysed with $1 \mathrm{ml} \mathrm{rbc} \mathrm{lysis} \mathrm{buffer}\left(150 \mathrm{mM} \mathrm{NH}_{4} \mathrm{Cl}, 10 \mathrm{mM} \mathrm{NaHCO}_{3}\right.$, $0.1 \mathrm{mM}$ EDTA) for $30-40$ seconds at room temperature, and lysis was quenched with $4 \mathrm{ml}$ RPMI. Cell suspensions were counted using a Cellometer Auto T4 (Nexcelom) or Scepter (Millipore) and were seeded at $1.3 \times 10^{6}$ to $2 \times 10^{6}$ cells (equal density within a given experiment) in 96-well round-bottom plates for staining. For cytokine analyses, cells were stimulated overnight with PMA (100 ng/ml; Sigma-Aldrich) and ionomycin $(500 \mathrm{ng} / \mathrm{ml}$; Fisher Scientific). GolgiPlug (1:1,000; BD Biosciences) was added to the existing medium, and cells were cultured an additional 3.5-4 hours before staining. Cells were stained for $15 \mathrm{~min}$ utes at $4^{\circ} \mathrm{C}$ in FACS buffer ( $2 \% \mathrm{FBS} / 1 \times \mathrm{PBS}$ ) with antibodies to surface antigens, stained for 10 minutes at $4^{\circ} \mathrm{C}$ in $1 \times \mathrm{PBS}$ with eFluor780 viability dye (eBioscience), fixed and permeabilized for 15 minutes at room temperature in Fixation/Permeabilization reagent (eBioscience), and stained for 45 minutes at room temperature in $1 \times$ Permeabilization Buffer (eBioscience) with antibodies to intracellular proteins. Cells were washed in FACS buffer before surface staining, viability dye staining, and fixation, and washed with $1 \times$ Permeabilization Buffer before and after intracellular staining. The following antibodies (clones) were purchased from BioLegend: Ki67 A647 (16A8), Tim-3 PE (RMT3-23), CD8a PE-Cy7 (53-6.7), CD45 A488 (30-F11), CD44 PerCP-Cy5.5 (IM7), PD-1 BV421 (29F.1A12), CD4 BV510 (GK1.5), IFN- $\gamma$ A647 (XMG1.2), TNF- $\alpha$ BV421 (MP6-XT22), LAG-3 BV650 (C9B7W), CD45 BV785 (30-F11), PD-L1 PE (10F.9G2), IgG2b $\kappa$ isotype control (RTK4530). The following antibodies (clones) were purchased from BD Biosciences: CD25 PE-CF594 (PC61), TCR $\beta$ PE-Cy7 (H57-597), CD8a BB515 (53-6.7), LAG-3 BV650 (C9B7W), CD62L BV786 (MEL-14), IL-2 PE-Cy7 (JES65H4), CD4 BV650 (GK1.5). Foxp3 A700 (FJK-16s) antibody was purchased from eBioscience. Uncompensated data were collected using an LSRFortessa cytometer with FACSDiva software (both BD Biosciences). Compensation and analyses were performed using FlowJo v10 software. OneComp eBeads (eBioscience) were used for singlecolor compensation controls for LAG-3, Tim-3, PD-1 (CT26 day 12 and $\mathrm{Kras}^{\mathrm{G12D}} / \mathrm{Twist1}$ ), and Foxp3 (CT26 cytokine and Kras ${ }^{G 12 D} /$ Twist1). Splenocytes were used for all other compensation controls. Gating strategies are included in the supplementary material (Supplemental Figure
4A for CT26 tumor PD-L1 expression, Supplemental Figures 17 and 18 for $\mathrm{T}$ cell immune profiling and $\mathrm{T}$ cell cytokine production, respectively, in CT26 tumor-bearing mice, and Supplemental Figure 19 for T cell immune profiling in $\mathrm{Kras}^{\mathrm{GI2D}}$ /Twist1 lung adenocarcinoma mice). Data represented as the number per $10^{4}$ cells stained were calculated by multiplication of the number of cells stained by the percentage of total events above threshold (after exclusion of any unstable portions of the run).

Analysis of CT26 PD-L1 expression in vitro. CT26 cells were treated with AZD6738 (300 nM) or DMSO vehicle (0.25\%) immediately before receiving $6 \mathrm{~Gy}$ radiation in a ${ }^{137} \mathrm{Cs}$ irradiator at a rate of $327 \mathrm{cGy} / \mathrm{min}$. Cells were stained for 30 minutes at $4^{\circ} \mathrm{C}$ with anti-PD-L1 PE (1OF.9G2) or IgG2b $\kappa$ isotype control (RTK4530), both purchased from BioLegend and used at 1:100. Analyses were performed using an Accuri C6 cytometer and CFlow software (both BD Biosciences). Following SSC-A versus FSC-A gating and doublet exclusion (SSC-H vs. SSC-A), background-corrected PD-L1 median fluorescence intensity (PD-L1 MFI isotype control MFI for each treatment condition) was determined.

Statistics. For CT26 treatment response and CD8 depletion experiments, statistical significance was determined by comparison of the change in tumor volume (from day 1 ) at a given time point by ANOVA with Holm-Šidák multiple-comparisons test (family-wise significance 0.05 , all pairwise comparisons performed) at time points with more than 2 groups remaining on study, or by unpaired, 2-tailed $t$ test (95\% confidence level) at time points with only 2 groups remaining. For CT26 response experiments, statistical significance is graphically displayed only for comparisons at the final measurement time point. For Kras ${ }^{G 12 D} /$ Twist1 lung adenocarcinoma treatment response and CD8 depletion experiments, statistical significance was determined comparing percentage tumor growth (from day 0) at a given time point by ANOVA with Holm-Šidák multiple-comparisons test (familywise significance 0.05 , all pairwise comparisons performed). For all CD8 depletion experiments, only pairwise comparisons among CD8depleted treatment groups were performed. For immune profiling and in vitro experiments, statistical significance was determined by ANOVA with Tukey's multiple-comparison tests (95\% confidence level), except for $\mathrm{Kras}^{\mathrm{G12D}} / \mathrm{Twist} \mathrm{T}$ cell immune profiling at day 5 (AZD6738 alone vs. untreated control), which was determined by unpaired, 2-tailed $t$ test (95\% confidence interval). Data are reported as mean $\pm \mathrm{SD}$, except for CT26 treatment response data, where changes in tumor volume from day 1 are reported as mean \pm SEM. All statistical analyses were performed in GraphPad Prism 7.

Study approval. Experimental procedures were approved by the University of Pittsburgh and Johns Hopkins University Animal Care and Use Committees and performed in accordance with the relevant guidelines and regulations.

\section{Author contributions}

FPV, PK, DAC, TT, RL, KN, MB, BFK, JHB, PTT, GMD, and CJB designed, executed, and analyzed experiments. SNS, TPC, MJO, and RLF provided advice or reagents. FPV, DAC, GMD, and CJB wrote the manuscript.

\section{Acknowledgments}

We thank University of Pittsburgh Medical Center radiation physicists Fang Li and S. Young Jang for technical assistance with our experiments. This work was funded by NIH grants R01CA204173 (to CJB), P50CA097190 (to DAC), and R01CA166348 (to PTT); 
Sidney Kimmel Foundation grant SKF-015-039 and Stand Up 2 Cancer grant SU2C-AACR-IRG-04-16 (to GMD); and NIH grant P30CA047904 (to RLF).
Address correspondence to: Christopher J. Bakkenist, Hillman Cancer Center, 2.6, 5117 Centre Avenue, Pittsburgh, Pennsylvania 15232, USA. Phone: 412.623.7765; Email: bakkenistcj@upmc.edu.
1. Ohaegbulam KC, Assal A, Lazar-Molnar E, Yao $\mathrm{Y}$, Zang X. Human cancer immunotherapy with antibodies to the PD-1 and PD-L1 pathway. Trends Mol Med. 2015;21(1):24-33.

2. Pardoll DM. The blockade of immune checkpoints in cancer immunotherapy. Nat Rev Cancer. 2012;12(4):252-264.

3. Keir ME, Butte MJ, Freeman GJ, Sharpe AH. PD-1 and its ligands in tolerance and immunity. Annu Rev Immunol. 2008;26:677-704.

4. Barber DL, et al. Restoring function in exhausted CD8 T cells during chronic viral infection. Nature. 2006;439(7077):682-687.

5. Liang SC, et al. Regulation of PD-1, PD-L1, and PD-L2 expression during normal and autoimmune responses. Eur JImmunol. 2003;33(10):2706-2716.

6. Dong $\mathrm{H}$, et al. Tumor-associated $\mathrm{B} 7-\mathrm{H} 1$ promotes T-cell apoptosis: a potential mechanism of immune evasion. Nat Med. 2002;8(8):793-800.

7. Hirahara K, et al. Interleukin-27 priming of $\mathrm{T}$ cells controls IL-17 production in trans via induction of the ligand PD-L1. Immunity. 2012;36(6):1017-1030.

8. Spranger S, et al. Up-regulation of PD-L1, IDO, and $\mathrm{T}$ (regs) in the melanoma tumor microenvironment is driven by CD8(+) T cells. Sci Transl Med. 2013;5(200):200ra116.

9. Deng L, et al. Irradiation and anti-PD-L1 treatment synergistically promote antitumor immunity in mice. J Clin Invest. 2014;124(2):687-695.

10. Topalian SL, et al. Safety, activity, and immune correlates of anti-PD-1 antibody in cancer. $N$ Engl JMed. 2012;366(26):2443-2454.

11. Brahmer JR, et al. Safety and activity of antiPD-L1 antibody in patients with advanced cancer. N Engl J Med. 2012;366(26):2455-2465.

12. Ferris RL, et al. Nivolumab for recurrent squamous-cell carcinoma of the head and neck. N Engl JMed. 2016;375(19):1856-1867.

13. Ciccia A, Elledge SJ. The DNA damage response: making it safe to play with knives. Mol Cell. 2010;40(2):179-204.

14. Burnette BC, et al. The efficacy of radiotherapy relies upon induction of type i interferondependent innate and adaptive immunity. Cancer Res. 2011;71(7):2488-2496.

15. Gupta A, et al. Radiotherapy promotes tumor-specific effector $\mathrm{CD}^{+} \mathrm{T}$ cells via dendritic cell activation. J Immunol. 2012;189(2):558-566.

16. Lee Y, et al. Therapeutic effects of ablative radiation on local tumor require $\mathrm{CD} 8+\mathrm{T}$ cells: changing strategies for cancer treatment. Blood. 2009;114(3):589-595.

17. Reits EA, et al. Radiation modulates the peptide repertoire, enhances MHC class I expression, and induces successful antitumor immunotherapy. JExp Med. 2006;203(5):1259-1271.

18. Kachikwu EL, et al. Radiation enhances regulatory T cell representation. Int J Radiat Oncol Biol Phys. 2011;81(4):1128-1135.
19. Dovedi SJ, et al. Acquired resistance to fractionated radiotherapy can be overcome by concurrent PD-L1 blockade. Cancer Res. 2014;74(19):5458-5468.

20. Twyman-Saint Victor C, et al. Radiation and dual checkpoint blockade activate nonredundant immune mechanisms in cancer. Nature. 2015;520(7547):373-377.

21. Zeng J, et al. Anti-PD-1 blockade and stereotactic radiation produce long-term survival in mice with intracranial gliomas. Int J Radiat Oncol Biol Phys. 2013;86(2):343-349.

22. Herter-Sprie GS, et al. Synergy of radiotherapy and PD-1 blockade in Kras-mutant lung cancer. JCI Insight. 2016;1(9):e87415.

23. Cimprich KA, Shin TB, Keith CT, Schreiber SL. cDNA cloning and gene mapping of a candidate human cell cycle checkpoint protein. Proc Natl Acad Sci U S A. 1996;93(7):2850-2855.

24. Brown EJ, Baltimore D. ATR disruption leads to chromosomal fragmentation and early embryonic lethality. Genes Dev. 2000;14(4):397-402.

25. de Klein A, et al. Targeted disruption of the cell-cycle checkpoint gene ATR leads to early embryonic lethality in mice. Curr Biol. 2000;10(8):479-482.

26. Prevo R, et al. The novel ATR inhibitor VE-821 increases sensitivity of pancreatic cancer cells to radiation and chemotherapy. Cancer Biol Ther. 2012;13(11):1072-1081.

27. Charrier JD, et al. Discovery of potent and selective inhibitors of ataxia telangiectasia mutated and Rad3 related (ATR) protein kinase as potential anticancer agents. JMed Chem. 2011;54(7):2320-2330.

28. Reaper PM, et al. Selective killing of ATM- or p53-deficient cancer cells through inhibition of ATR. Nat Chem Biol. 2011;7(7):428-430.

29. Gamper AM, Rofougaran R, Watkins SC, Greenberger JS, Beumer JH, Bakkenist CJ. ATR kinase activation in $\mathrm{G} 1$ phase facilitates the repair of ionizing radiation-induced DNA damage. Nucleic Acids Res. 2013;41(22):10334-10344

30. Pires IM, et al. Targeting radiation-resistant hypoxic tumour cells through ATR inhibition. Br J Cancer. 2012;107(2):291-299.

31. Hammond EM, Denko NC, Dorie MJ, Abraham RT, Giaccia AJ. Hypoxia links ATR and p53 through replication arrest. Mol Cell Biol. 2002;22(6):1834-1843.

32. Hammond EM, Dorie MJ, Giaccia AJ. ATR/ATM targets are phosphorylated by ATR in response to hypoxia and ATM in response to reoxygenation. J Biol Chem. 2003;278(14):12207-12213.

33. Hammond EM, Dorie MJ, Giaccia AJ. Inhibition of ATR leads to increased sensitivity to hypoxia/reoxygenation. Cancer Res. 2004;64(18):6556-6562.

34. Vendetti FP, Lau A, Schamus S, Conrads TP, O'Connor MJ, Bakkenist CJ. The orally active and bioavailable ATR kinase inhibitor AZD6738 potentiates the anti-tumor effects of cisplatin to resolve ATM-deficient nonsmall cell lung cancer in vivo. Oncotarget. 2015;6(42):44289-44305.

35. Hall AB, et al. Potentiation of tumor responses to DNA damaging therapy by the selective ATR inhibitor VX-970. Oncotarget. 2014;5(14):5674-5685.

36. Studies found for: AZD6738. National Institutes of Health. https://clinicaltrials.gov/ ct $2 /$ results?cond $=\&$ term $=$ AZD 6738\&cntry $=\&$ state $=\&$ city $=\&$ dist $=$. Accessed July 31, 2018.

37. AZD6738: Preclinical pharmacology. AstraZeneca website. https://openinnovation.astrazeneca. com/azd6738.html. Accessed July 6, 2018.

38. Vendetti FP, et al. Pharmacologic ATM but not ATR kinase inhibition abrogates p21-dependent G1 arrest and promotes gastrointestinal syndrome after total body irradiation. Sci Rep. 2017;7:41892.

39. Castle JC, et al. Immunomic, genomic and transcriptomic characterization of CT26 colorectal carcinoma. BMC Genomics. 2014;15:190.

40. Sato $\mathrm{H}$, et al. DNA double-strand break repair pathway regulates PD-L1 expression in cancer cells. Nat Commun. 2017;8(1):1751.

41. Lau J, et al. Tumour and host cell PD-L1 is required to mediate suppression of anti-tumour immunity in mice. Nat Commun. 2017;8:14572.

42. Simon S, Labarriere N. PD-1 expression on tumor-specific T cells: friend or foe for immunotherapy? Oncoimmunology. 2017;7(1):e1364828.

43. Xu-Monette ZY, Zhang M, Li J, Young KH. PD-1/ PD-L1 Blockade: have we found the key to unleash the antitumor immune response? Front Immunol. 2017;8:1597.

44. Wherry EJ, Kurachi M. Molecular and cellular insights into T cell exhaustion. Nat Rev Immunol. 2015;15(8):486-499.

45. Blackburn SD, et al. Coregulation of CD8+ T cell exhaustion by multiple inhibitory receptors during chronic viral infection. Nat Immunol. 2009;10(1):29-37.

46. Sakuishi K, Apetoh L, Sullivan JM, Blazar BR, Kuchroo VK, Anderson AC. Targeting Tim-3 and PD-1 pathways to reverse T cell exhaustion and restore anti-tumor immunity. J Exp Med. 2010;207(10):2187-2194.

47. Fourcade J, et al. Upregulation of Tim-3 and PD-1 expression is associated with tumor antigenspecific $\mathrm{CD}^{+} \mathrm{T}$ cell dysfunction in melanoma patients. J Exp Med. 2010;207(10):2175-2186.

48. Tran PT, et al. Twist1 suppresses senescence programs and thereby accelerates and maintains mutant Kras-induced lung tumorigenesis. PLOS Genet. 2012;8(5):e1002650.

49. Saenz SA, et al. IL-25 simultaneously elicits distinct populations of innate lymphoid cells and multipotent progenitor type 2 (MPPtype2) cells. JExp Med. 2013;210(9):1823-1837.

50. McNally JP, et al. Manipulating DNA damageresponse signaling for the treatment of immune-mediated diseases. Proc Natl Acad Sci U S A. 2017;114(24):E4782-E4791. 